\title{
Binding to Gating Transduction in Nicotinic Receptors: Cys- Loop Energetically Couples to Pre-M1 and M2-M3 Regions
}

\author{
Won Yong Lee, ${ }^{1,2}$ Chris R. Free,,$^{1,2}$ and Steven M. Sine ${ }^{1,2,3}$ \\ ${ }^{1}$ Receptor Biology Laboratory and Departments of 2 Physiology and Biomedical Engineering and ${ }^{3}$ Neurology, Mayo Clinic College of Medicine, Rochester, \\ Minnesota 55905
}

\begin{abstract}
The nicotinic acetylcholine receptor $(\mathrm{AChR})$ transduces binding of nerve-released $\mathrm{ACh}$ into opening of an intrinsic ion channel, yet the intraprotein interactions behind transduction remain to be fully elucidated. Attention has focused on the region of the AChR in which the $\beta 1-\beta 2$ and Cys-loops from the extracellular domain project into a cavity framed by residues preceding the first transmembrane domain (pre-M1) and the linker spanning transmembrane domains M2 and M3. Previous studies identified a principal transduction pathway in which the pre-M1 domain is coupled to the M2-M3 linker through the $\beta 1-\beta 2$ loop. Here we identify a parallel pathway in which the pre-M1 domain is coupled to the M2-M3 linker through the Cys-loop. Mutagenesis, single-channel kinetic analyses and thermodynamic mutant cycle analyses reveal energetic coupling among $\alpha$ Leu 210 from the pre-M1 domain, $\alpha$ Phe 135 and $\alpha$ Phe 137 from the Cys-loop, and $\alpha$ Leu 273 from the M2-M3 linker. Residues at equivalent positions of non- $\alpha$-subunits show negligible coupling, indicating these interresidue couplings are specific to residues in the $\alpha$-subunit. Thus, the extracellular $\beta 1-\beta 2$ and Cys-loops bridge the pre-M1 domain and M2-M3 linker to transduce agonist binding into channel gating.
\end{abstract}

\section{Introduction}

Rapid synaptic transmission comprises quantal release of neurotransmitter, followed by activation of postsynaptic receptors. The core function of postsynaptic receptors is to bind the neurotransmitter and then transduce binding into opening of an ion channel several tens of angstroms from the binding site. Atomic-scale insight into the transduction process is now possible because of high-resolution x-ray structures of prokaryotic receptor ancestors (Hilf and Dutzler, 2008; Bocquet et al., 2009), the isolated binding domains (Armstrong et al., 1998; Dellisanti et al., 2007), homologs of the binding domains (Brejc et al., 2001; Hansen et al., 2005), and a 4-Å-resolution cryo-electron microscopic structure of the Torpedo AChR (Unwin, 2005). Given residue locations within functionally crucial regions of synaptic receptors, structural, electrophysiological, and computational approaches provide powerful means to identify intraprotein structures that transduce neurotransmitter binding into channel gating.

The AChR from the motor endplate has served as a prototype to understand receptor-coupled ion channels from the Cys-loop receptor superfamily. The AChR contains five homologous subunits arranged as barrel-staves around a central ion-conducting pore. Each subunit contains a large extracellular domain composed primarily of $\beta$-sheets, a pore domain composed of four transmembrane $\alpha$-helices, and a cytoplasmic domain composed of partially defined $\alpha$-helical structure (Unwin, 2005). Transduction begins with binding of ACh to each of two sites located at

Received Dec. 30, 2008; revised Feb. 5, 2009; accepted Feb. 6, 2009.

This work was supported by National Institutes of Health Grant NS031744 (S.M.S.).

Correspondence should be addressed to Steven M. Sine at the above address. E-mail: sine@mayo.edu.

W. Y. Lee's present address: Department of Biology, University of Utah, Salt Lake City, UT 84112.

DOI:10.1523/JNEUROSCI.6185-08.2009

Copyright $\odot 2009$ Society for Neuroscience $\quad$ 0270-6474/09/293189-11\$15.00/0 interfaces between extracellular regions of $\alpha$ - and either $\varepsilon$ - or $\delta$-subunits. After ACh enters each binding site, a hairpin structure called the C-loop changes from an open to a closed conformation that traps ACh within the site. One $\beta$-strand from each C-loop extends to the junction of the extracellular and pore domains where it forms the pre-M1 region that covalently links the two domains. Two loops from the extracellular domain, the $\beta 1-$ $\beta 2$ - and Cys-loops, also project into the interdomain junction (Fig. 1). The $\beta 1-\beta 2$ loop is a key element of a principal pathway that transduces ACh binding into channel gating, and through a series of interresidue contacts, functionally couples the pre-M1 domain to the linker spanning the M2 and M $3 \alpha$-helices from the pore domain (Lee and Sine, 2005). The Cys-loop is situated adjacent to the $\beta 1-\beta 2$ loop, where it also bridges the pre-M1 domain and M2-M3 linker (Unwin, 2005). Found in all subunits in the superfamily of Cys-loop receptors, the Cys-loop is essential for AChR assembly (Fu and Sine, 1996; Green and Wanamaker, 1997) and rapid and efficient gating of the AChR channel (Jha et al., 2007).

Here we show that contributions of the Cys-loop to channel gating depend on residues in the pre-M1 domain and the M2-M3 linker. Site-directed mutagenesis, single-channel kinetic analyses, and thermodynamic mutant cycle analyses reveal strong energetic coupling among $\alpha$ Phe 135 and $\alpha$ Phe 137 from the Cysloop, $\alpha$ Leu 210 from the pre-M1 domain, and $\alpha$ Leu 273 from the M2-M3 linker. The overall findings show that the $\beta 1-\beta 2$ and Cys-loops form functionally parallel transduction pathways linking the pre-M1 domain to the M2-M3 linker.

\section{Materials and Methods}

\section{Construction of wild-type and mutant AChRs}

Human $\alpha$-, $\beta$-, $\delta$-, and $\varepsilon$-subunit cDNAs were subcloned in the CMVbased mammalian expression vector pRBG4 (Lee et al., 1991) as de- 

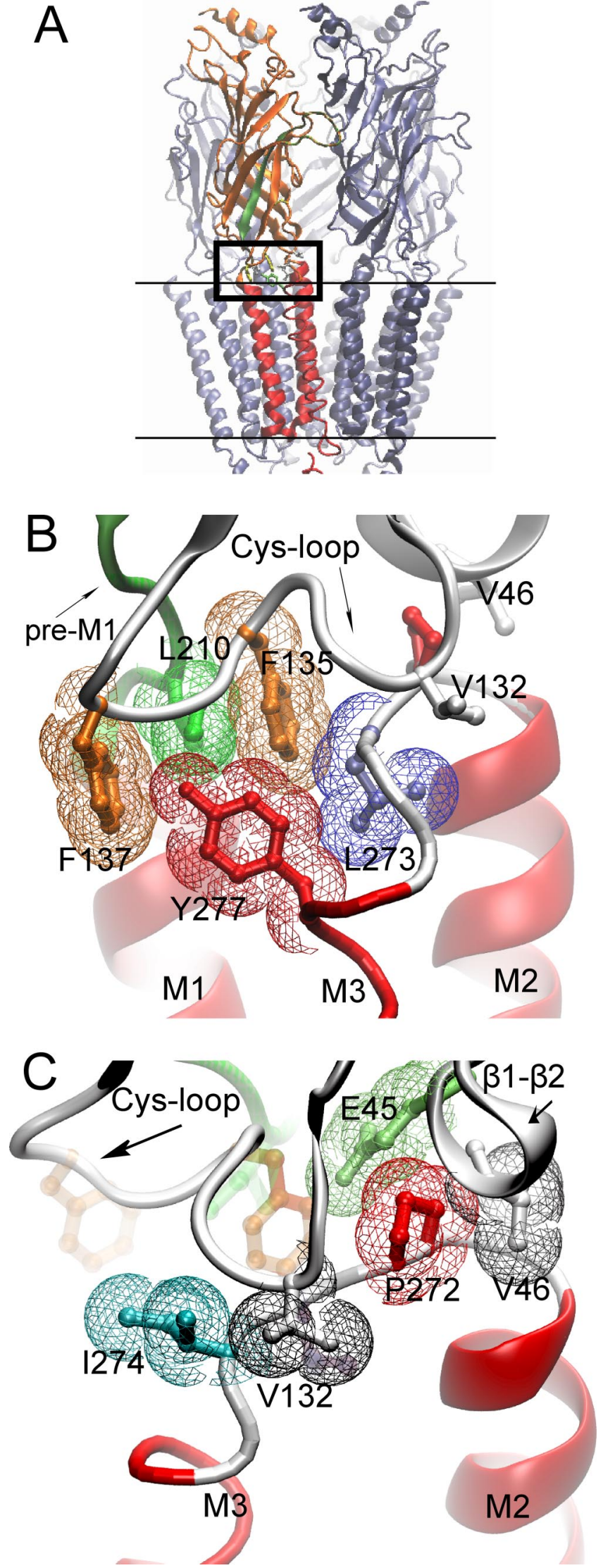

Figure 1. Cryo-electron microscopic structure of the Torpedo AChR (PDB code 2bg9). $A$, The pentameric AChR in the membrane (parallel lines) is shown with one of the two $\alpha$-subunits highlighted; $\beta$-strands are orange and $\alpha$-helices red. $\beta$-Strand 10 preceding transmembrane domain $\mathrm{M} 1$ region is green. The boxed region is the junction of extracellular and pore domains, scribed (Ohno et al., 1996). Site-directed mutations were made using the QuikChange Site-Directed Mutagenesis Kit (Stratagene). The presence of each mutation and the absence of unwanted mutations were confirmed by sequencing the entire cDNA insert.

\section{Mammalian cell expression}

All experiments were performed using the BOSC 23 cell line (CRL11270, ATCC), a variant of the HEK 293 cell line. Cells were maintained in the DMEM containing FBS $(10 \% \mathrm{v} / \mathrm{v})$ at $37^{\circ} \mathrm{C}$ until they reached $\sim 50-70 \%$ confluence. Wild-type or mutant AChR cDNAs plus the cDNA encoding green fluorescent protein were transfected by calciumphosphate precipitation using final concentrations of each cDNA of 0.68 $\mu \mathrm{g} / \mathrm{ml}$. Patch-clamp recordings were performed $1-2 \mathrm{~d}$ after transfection.

\section{Patch-clamp single-channel recordings}

To record single-channel currents, cells transfected with wild-type or mutant AChR cDNAs were rinsed with and maintained in the following bath solution (in mM): $\mathrm{KCl} 142, \mathrm{NaCl} 5.4, \mathrm{CaCl}_{2} 1.8, \mathrm{MgCl}_{2} 1.7$, and HEPES 10 (pH was adjusted to 7.4 with $\mathrm{NaOH}$ ). The same solution was used to fill patch pipettes. ACh (Sigma-Aldrich) was kept as a $10 \mathrm{~mm}$ stock in bath solution and stored at $-80^{\circ} \mathrm{C}$ until use. Glass micropipettes (type 7052; Garner Glass) were coated with Sylgard 184 (Dow Corning) and heat polished to yield resistances of 5-8 M $\Omega$. After identifying transfected cells under fluorescence optics, single-channel currents were recorded in the cell-attached configuration using the Axopatch 200A (Molecular Devices) at a holding membrane potential of $-70 \mathrm{mV}$ at $22^{\circ} \mathrm{C}$. Data were collected from two to four different patches for each ACh concentration, choosing only recordings in which channel activity was low enough to allow identification of activation episodes resulting from a single AChR channel. The current signal was low-pass filtered at $50 \mathrm{kHz}$ and recorded to hard disk at $200 \mathrm{kHz}$ using the program Acquire (Bruxton). Recordings of single-channel currents spanning a range of $\mathrm{ACh}$ concentrations from each mutant receptor were typically performed over a period of $12 \mathrm{~h}$.

\section{Single-channel kinetic analysis}

Detailed methods of single-channel kinetic analyses were described previously (Lee and Sine, 2004). Briefly, the digitized current signal was filtered using a $10 \mathrm{kHz}$ digital Gaussian filter (Colquhoun and Sigworth, 1983). Channel events were detected by the half-amplitude threshold criterion using the program TAC (Bruxton) with an imposed dead time of $10 \mu \mathrm{s}$. Precise determination of each dwell time at threshold was achieved by cubic spline interpolation of the digital signal, and the measured dwell time at threshold was corrected for the effects of the Gaussian filter (Colquhoun and Sigworth, 1983). Open and closed time histograms were fitted by the sum of exponentials by maximum likelihood using the program TACFit (Bruxton). Openings corresponding to a single receptor channel were identified by assigning a critical closed time defined as the point of intersection of the closed time component that depended on ACh concentration with the succeeding concentrationindependent component (Ohno et al., 1996), presumably due to fast desensitization. Because this method removes most but not all closed dwell times due to fast desensitization, analyses were also performed in which the critical closed time was defined as the point of intersection of the closed time component due to fast desensitization with the succeeding component, and the scheme was modified to include a desensitized state connected to the doubly occupied open state. To obtain kinetically homogeneous data, defined single-channel episodes containing at least five openings were analyzed for channel open probability, mean open time, and mean closed time; episodes within two SDs of the mean were accepted for further analysis (Wang et al., 1997). This processing re-

\section{$\leftarrow$}

shown at higher magnification in $\boldsymbol{B}$ and $\boldsymbol{C}$. $\boldsymbol{B}$, Residues from three converging regions of the $\alpha$-subunit (Cys-loop, pre-M1 strand, M2-M3 linker) are shown in stick representation overlaid with colored van der Waals surfaces. $\boldsymbol{C}$, The region in $\boldsymbol{B}$ is rotated to the left to illustrate residues with aliphatic side chains from the Cys-loop, $\beta 1-\beta 2$ loop, and M2-M3 linker. 


\begin{tabular}{|c|c|c|c|}
\hline & Cys-loop & pre-M1 & M2-M3 \\
\hline & $\begin{array}{c}135 \\
*\end{array}$ & 210 & $\begin{array}{c}273 \\
*\end{array}$ \\
\hline nAChR $\propto 1$ Human & CEIIVTHFPFDEQNC & QRLPLYFIVNVI & PSTSSAVPLIGKY \\
\hline nAChR $\alpha 1$ Torpedo & CEIIVTHFPFDQQNC & QRIPLYFVVNVI & PSTSSAVPLIGKY \\
\hline nAChR $\alpha 2$ Human & CSIDVTFFPFDQQNC & RRLPLEYTINLI & PSTSLVIPLIGEY \\
\hline nAChR $\propto 3$ Human & CKIDVTYFPFDYQNC & RRLPLFYTINLI & PSTSLVIPLIGEY \\
\hline nAChR $\propto 4$ Human & CSIDVTFFPFDQQNC & RRLPLEYTINLI & PSTSLVIPLIGEY \\
\hline $\mathrm{nAChR} \alpha 5$ Human & CTIDVTFFPFLQNC & KRLPLEYTLELI & PSSSKVIPLIGEY \\
\hline $\mathrm{nAChR} \alpha 6$ Human & CPMDITFFPFDHQNC & RRLPMEYTINLI & PSTSLVVPLVGEY \\
\hline nAChR $\propto 7$ Human & CYIDVRWFPFDVQHC & RRRTLYYGLNLL & PATSDSVPLIAQY \\
\hline nAChR $\propto 9$ Human & CVVDVTYFPFDNQQC & KRRSSEYIVNLL & PA-SENVPLIGKY \\
\hline nAChR $\propto 10$ Human & CRVDVAAF PFDAQHC & RRRAAAYVCNLL & PP-AESVPLIGKY \\
\hline nAChR $\beta$ Human & CSIQVTYFPEDWQNC & RRKPLEYLVNVI & PETSLSVPIIIKY \\
\hline nAChR $\delta$ Human & CPISVTYFPFDWQNC & RRKPLEYIINIL & PAT SMAI PLIGKF \\
\hline nAChR $\varepsilon$ Human & CAVEVTYFPFDWQNC & RRKPLEYVINII & PETSLSVPLLGRF \\
\hline 5-HT3A Human & CSLDIYNFPEDVQNC & RRRPLEYVVSLL & PATAIGTPLIGVY \\
\hline 5-HT3E Human & CNLDIFYFPFDQQNC & RRRPSLYVINLL & PTS--GTPLIGVY \\
\hline GABA $\alpha 1$ Human & CPMHLEDFPMDAHAC & KRKIGYFVIQTY & P-KVAYATAMDWF \\
\hline GABA $\alpha 2$ Human & CPMHLEDFPMDAHSC & KRKIGYFVIQTY & P-KVAYATAMDW F \\
\hline GABA $\alpha 3$ Human & CPMHLEDFPMDVHAC & KRKIGYFVIQTY & P-KVAYATAMDWF \\
\hline GABA $\alpha \leq$ Human & CPMRLVDFPMDGHAC & RRKMGYFMIQTY & P-KVSYLTAMDWF \\
\hline GABA $\alpha 5$ Human & CPMQLEDFPMDAHAC & KRKIGYEVIQTY & P-KVAYATAMDWF \\
\hline GABA $\alpha 6$ Human & CPMRLVNFPMDGHAC & QRKMGYFMIQIY & P-KVSYATAMDWF \\
\hline GABA $\beta 1$ Human & CMMDLRRYPLDEQNC & KRNIGYFILQTY & P-KIPYVKAIDIY \\
\hline GABA $\beta 2$ Human & CMMDLRRY PLDEQNC & KRN I GY FILQTY & P-KIPYVKAIDMY \\
\hline GABA $\beta 3$ Human & CMMDLRRYPLDEQNC & KRNIGYFILQTY & P-KIPYVKAIDMY \\
\hline GABA $\delta$ Human & CDMDLAKY PMDEQEC & RRNRGVYIIQSY & P-RASAIKALDVY \\
\hline GABA $\rho$ Human & CNMDLSKYPMDTQTC & RRNVLYFILETY & PNTNCFIKAIDVY \\
\hline GABA $Y 1$ Human & CNMDFSRFPLDTQTC & RRHIFEFLLQTY & P-RVSYIKAVDIY \\
\hline GABA Y2 Human & CNMDFSHFPLDSQTC & RRHIFFFLLQTY & P-RVSYVKAVDIY \\
\hline GlyR $\alpha 1$ Human & CPMDLKNFPMDVQTC & ERQMGYYLIQMY & P-KVSYVKAIDIW \\
\hline GlyR $\alpha 2$ Human & CPMDLKNFPMDVQTC & ERQMGYYLIQMY & P-KVSYVKAIDIW \\
\hline GlyR $\alpha 3$ Human & CPMDLKNFPMDVQTC & ERQMGYYLIQMY & P-KVSYVKAIDIW \\
\hline GlyR $\beta$ Human & CPLDLTLFPMDTQRC & RRQVGEYMMGVY & P-KVSYVKALDVW \\
\hline ELIC & NDMDFRLFPFDRQQF & VRNPSYYLWSFI & P-RLPYTTVIDQM \\
\hline GLIC & SPLDFRRYPFDSQTL & SRQYFSYIPNII & P-KTPYMTYTGAI \\
\hline
\end{tabular}

Figure 2. Sequence alignment of subunits from the Cys-loop receptor superfamily. Structural regions examined in the text are labeled (top) with residues at positions equivalent to $\alpha$ Phe 135, $\alpha$ Phe 137, $\alpha$ Leu 210, $\alpha$ Leu 273, $\alpha$ lle 274, $\alpha$ Val 132, and $\alpha$ Tyr 277 highlighted in bold.

moves a small population of single brief openings flanked by long closed periods (Sine and Steinbach, 1987). For receptors examined in this study, the overall selection retained $>80 \%$ of the detected single-channel events. The kinetic scheme was fitted simultaneously to all the data obtained over a range of ACh concentrations using MIL software (QuB suite, State University of New York, Buffalo), which employs a maximum likelihood optimization criterion, corrects for missed events, and computes error estimates of the fitted parameters (Qin et al., 1996). An instrument dead time of $22 \mu$ s was uniformly applied to all recordings. For a given wild-type or mutant receptor, our analysis comprised data from two to four patches for each ACh concentration, with the ACh concentrations spaced at half log-unit intervals over a two to three log-unit range of concentration. For each receptor mutant, the range of ACh concentrations spanned from the minimum to the maximum open channel probability.

The following kinetic scheme was fitted to the single-channel open and closed dwell times:

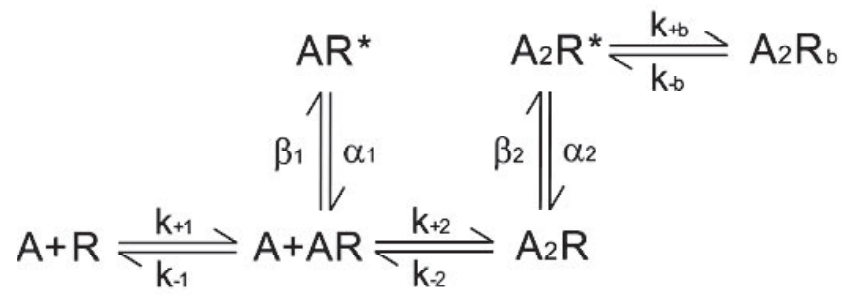

Two ACh (A) molecules associate with the receptor (R) with rate constants $k_{+1}$ and $k_{+2}$, and dissociate with rate constants $k_{-1}$ and $k_{-2}$. Closed but occupied receptors $\left(\mathrm{AR}\right.$ and $\left.\mathrm{A}_{2} \mathrm{R}\right)$ produce singly $\left(\mathrm{AR}^{\star}\right)$ and doubly $\left(\mathrm{A}_{2} \mathrm{R}^{\star}\right)$ occupied open states that close with rate constants $\alpha_{1}$ and $\alpha_{2}$, respectively. Rate constants for open channel blocking $\left(k_{+\mathrm{b}}\right)$ and unblocking $\left(k_{-\mathrm{b}}\right)$ by ACh are included.

\section{Double mutant cycle analysis}

To detect interresidue energetic coupling and estimate its magnitude, we applied mutant cycle analysis (Carter et al., 1984) to the diliganded gating equilibrium constant $\Theta_{2}$, computed from the ratio of rate constants $\beta_{2} / \alpha_{2}$ (Lee and Sine, 2005). The following mutant cycle examines energetic coupling between two residues, 1 and 2 , for which substitutions alter a functional parameter such as the channel gating equilibrium constant examined in the current study.

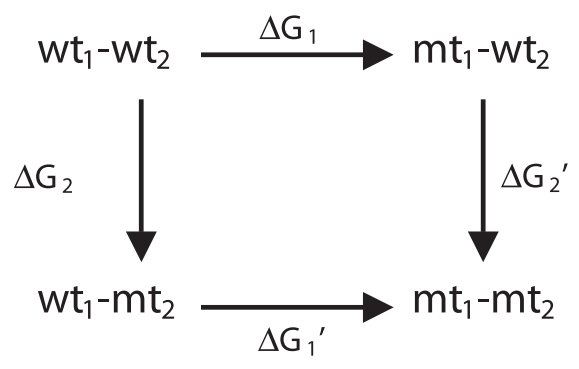

For each mutation (mt), the change in $\Theta_{2}$ relative to that of the wild-type (wt) AChR is expressed as $\Delta G=-R T \ln \left(\Theta_{2} \mathrm{mt} / \Theta_{2} \mathrm{wt}\right)$, where $R$ is the gas constant and $T$ the absolute temperature. The free energy change along either pathway from $\mathrm{wt}_{1}-\mathrm{wt}_{2}$ to $\mathrm{mt}_{1}-\mathrm{mt}_{2}$ is equal, expressed as $\Delta G_{1}+\Delta G_{2}{ }^{\prime}=\Delta G_{1}{ }^{\prime}+\Delta G_{2}$. Rearranging gives $\Delta G_{1}-\Delta G_{1}{ }^{\prime}=\Delta G_{2}-\Delta G_{2}{ }^{\prime}$, which gives the first-order coupling free energy for the mutant cycle, $\Delta \Delta G_{\text {int }}$. If the two residues are independent, $\Delta G_{1}=\Delta G_{1}{ }^{\prime}$ and $\Delta G_{2}=\Delta G_{2}{ }^{\prime}$, whereas if they are interdependent, $\Delta G_{1} \neq$ $\Delta G_{1}{ }^{\prime}$ and $\Delta G_{2} \neq \Delta G_{2}{ }^{\prime}$.

\section{Results}

Key residues from the Cys-loop, pre-M1 domain, and M2-M3 linker

At the border of the AChR extracellular and pore domains, an assembly of alternating aromatic and aliphatic residues lodges between the pre-M1 domain and the M2-M3 linker (Fig. 1A) (PDB code 2bg9) (Unwin, 2005). This assembly comprises $\alpha$ Leu 210 from the pre-M1 domain, $\alpha$ Phe 135 and $\alpha$ Phe 137 from the Cys-loop, and $\alpha$ Leu 273 from the M2-M3 linker (Fig. 1B). Although residue side chains are depicted with atomic precision, their precise placement is tentative because the resolution of the structure is $4 \AA$. Among subunits of the Cys-loop receptor superfamily, residues at positions equivalent to these are not conserved, but are hydrophobic or contain hydrophobic elements (Fig. 2). Furthermore, the four residues are conserved among $\alpha$-subunits that form heteromeric AChRs $\left(\alpha_{1}-\right.$ $\left.\alpha_{6}\right)$. Thus, location of the residues between the extracellular and pore domains and their sequence conservation, hydrophobicity, and apparent spatial continuity suggest that they form a functionally coupled network that contributes to the rapid and efficient channel gating characteristic of the AChR.

\section{Contributions of the four residues to channel gating}

Previous structure-function studies showed that $\alpha$ Phe 135, $\alpha$ Phe 137, $\alpha$ Leu 210, and $\alpha$ Leu 273 contribute to channel gating 
(Chakrapani et al., 2004; Jha et al., 2007; Purohit and Auerbach, 2007), but how the contributions depend on surrounding residues is not known. Furthermore, the contributions of $\alpha$ Phe 137 and $\alpha$ Leu 210 to channel gating have not been examined with ACh as the agonist. To provide a foundation to investigate functional interdependence of these residues, we constructed mutations of each residue, transfected BOSC 23 cells with cDNAs encoding each mutant $\alpha$-subunit, together with wild-type $\beta$-, $\varepsilon^{-}$, and $\delta$-subunit cDNAs, and recorded single-channel currents elicited by $\mathrm{ACh}$ (concentration range $3 \mu \mathrm{M}$ to $1 \mathrm{~mm}$ ). To identify mutations optimal for studying interresidue energetic coupling, we engineered different side chains at each position, recorded singlechannel currents activated by low and high concentrations of ACh, and chose mutations that produced large and readily measurable changes in single-channel closed and open dwell times (supplemental Fig. $\mathrm{S} 1$, available at www.jneurosci.org as supplemental material). Recordings of singlechannel currents show qualitatively that mutation of $\alpha$ Phe 135 to Leu decreases, whereas mutations of $\alpha$ Phe 137 to Leu, $\alpha$ Leu 210 to Gln, and $\alpha$ Leu 273 to Phe increase the probability of channel opening (Fig. 3). Thus, we chose these mutations for further study.

Changes in the probability of channel opening can arise from changes in rate constants underlying agonist binding or channel gating. To quantify the effect of each mutation on channel gating rate constants, we analyzed sequences of open and closed dwell times using a kinetic scheme in which two agonists bind sequentially followed by gating of the channel (see Materials and Methods). For each recording, long closed times corresponding to dwells in desensitized states were systematically removed, as described previously (Lee and Sine, 2004), and the kinetic scheme was fitted simultaneously to dwell time sequences elicited by the full range of $\mathrm{ACh}$ concentrations using the maximum likelihood optimization criterion (Qin et al., 1996). For both wild-type and mutant AChRs, probability density functions computed from the fitted rate constants superimpose well on histograms of closed and open dwell times (Fig. 3). Further, the fitted rate constants for channel opening and closing show that the mutation $\alpha \mathrm{F} 135 \mathrm{~L}$ decreases the channel gating equilibrium constant by $\sim 30$-fold, while the mutations $\alpha$ F137L, $\alpha$ L210Q, and $\alpha \mathrm{L} 273 \mathrm{~F}$ increase the gating equilibrium constant 1.5 -fold to fourfold (Table 1). Rate constants underlying agonist binding are also affected, with the greatest changes occurring for mutations that enhance channel gating.

\section{Energetic coupling between $\alpha$ Phe 135, $\alpha$ Leu 210, and $\alpha$ Leu 273}

The cryo-electron microscopic structure of the Torpedo AChR shows that $\alpha$ Leu 210 and $\alpha$ Leu 273 are predicted to bracket $\alpha$ Phe 135 (Fig. 1), suggesting these residues contribute to channel gating in an interdependent manner. To determine
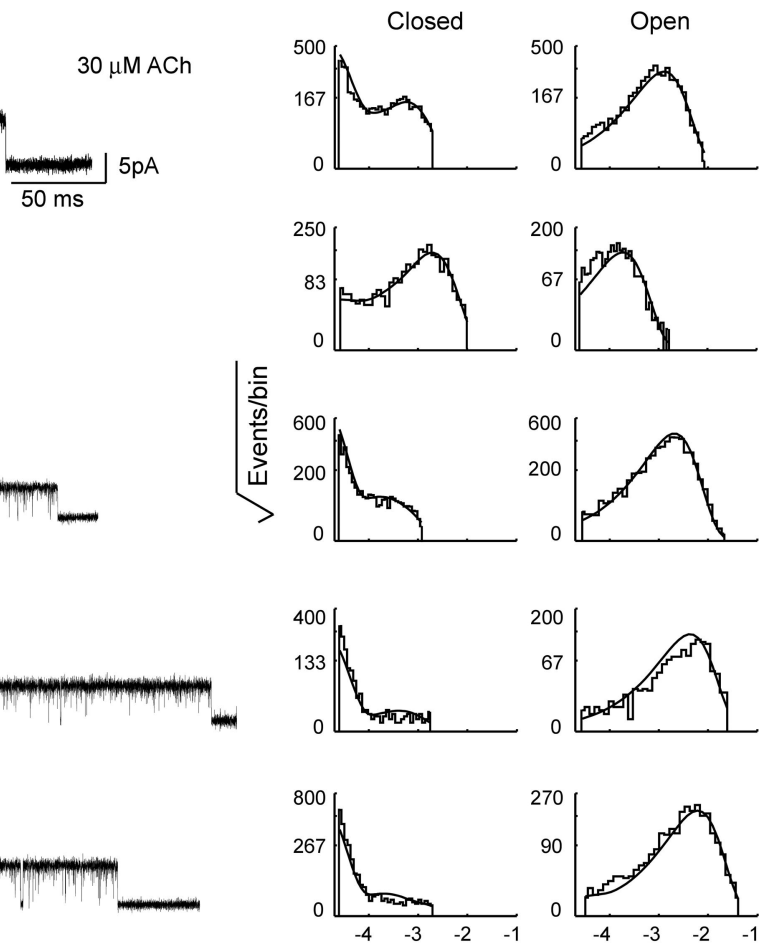

$\log$ Duration (sec)

Figure 3. Single-channel currents and dwell time histograms from AChRs containing the indicated mutations. Currents elicited 列 dimes within identified clusters of single-channel events are shown on logarithmic time axes with overlaid probability density functions generated from fitting a kinetic scheme simultaneously to data obtained over the entire range of ACh concentrations (see Materials and Methods; fitted rate constants are given in Table 1).

whether the residues' contributions are interdependent, we mutated each residue individually and in pairs, determined the channel gating equilibrium constant for each mutant $\mathrm{AChR}$, and cast the results as two-dimensional mutant cycles (Fig. 4). The mutation $\alpha$ F135L decreases the channel gating equilibrium constant by a free energy change of $1.9 \mathrm{kcal} / \mathrm{mol}$ relative to that of the wild-type AChR. However, if the mutation $\alpha \mathrm{L} 210 \mathrm{Q}$ is present in the same $\mathrm{AChR}, \alpha \mathrm{F} 135 \mathrm{~L}$ has a negligible effect on channel gating. Conversely, the mutation $\alpha \mathrm{L} 210 \mathrm{Q}$ increases the channel gating equilibrium constant by a free energy change of $-0.7 \mathrm{kcal} / \mathrm{mol}$, but when $\alpha \mathrm{F} 135 \mathrm{~L}$ is present in the same AChR, $\alpha \mathrm{L} 210 \mathrm{Q}$ enhances channel gating by a free energy change of $-2.6 \mathrm{kcal} / \mathrm{mol}$. The first-order coupling free energy, given by the difference between free energy changes for any two parallel lines of the $\alpha$ F135L/ $\alpha$ L210Q mutant cycle, is large, $-1.9 \mathrm{kcal} / \mathrm{mol}$; the negative sign indicates the double mutant enhances channel gating relative to that expected from additive contributions of the two single mutations. Analogously, the mutant cycle comprising the mutations $\alpha \mathrm{F} 135 \mathrm{~L}$ and $\alpha \mathrm{L} 273 \mathrm{~F}$ yields a first-order coupling free energy of $-1.1 \mathrm{kcal} / \mathrm{mol}$. Thus, the contribution of $\alpha$ Phe 135 to channel gating depends on both $\alpha$ Leu 210 and $\alpha$ Leu 273 .

To determine whether equivalent residues in the $\varepsilon$ - and $\delta$-subunits contribute to channel gating, and further, to determine whether any detected contributions are interdependent, we mutated each residue individually and in pairs, measured channel gating equilibrium constants for each mutant AChR, and generated two-dimensional mutant cycles (Fig. 4). Mutations of residues in the $\varepsilon$ - and $\delta$-subunits equivalent to $\alpha$ Phe 135 decrease 
Table 1. Kinetic analysis of AChRs with mutations in the $\alpha$-subunit

\begin{tabular}{|c|c|c|c|c|c|c|c|c|c|c|c|c|c|c|c|c|}
\hline AChR & $k_{+1}$ & $k_{-1}$ & $K_{1}(\mu \mathrm{m})$ & $k_{+2}$ & $k_{-2}$ & $K_{2}(\mu \mathrm{M})$ & $\beta_{1}$ & $\alpha_{1}$ & $\Theta_{1}$ & $\beta_{2}$ & $\alpha_{2}$ & $\mathrm{\theta}_{2}$ & $k_{+\mathrm{b}}$ & $k_{-b}$ & $K_{B}(\mathrm{mM})$ & $\Delta G^{\circ}(\mathrm{kcal} / \mathrm{mol})$ \\
\hline Wild type & $271 \pm 16$ & $7190 \pm 545$ & 26 & $192 \pm 6$ & $19,300 \pm 309$ & 101 & $67 \pm 8$ & $2190 \pm 160$ & $0.03 \pm 0.0043$ & $343,700 \pm 999$ & $1650 \pm 32$ & $26.5 \pm 0.79$ & $26 \pm 1$ & $113,000 \pm 1690$ & 4.3 & \\
\hline \multicolumn{17}{|l|}{ Mutant } \\
\hline$\alpha F 135 \mathrm{~L}$ & $146 \pm 33$ & $3760 \pm 992$ & 26 & $254 \pm 19$ & $26,600 \pm 1540$ & 105 & NA & NA & & $5980 \pm 100$ & $6230 \pm 55$ & $0.96 \pm 0.018$ & $20 \pm 2$ & $97,700 \pm 3560$ & 4.9 & $1.94 \pm 0.04$ \\
\hline$\alpha F 137 \mathrm{~L}$ & $185 \pm 12$ & $1780 \pm 166$ & 9.6 & $225 \pm 7.7$ & $11,100 \pm 271$ & 49 & NA & NA & & $85,600 \pm 2010$ & $2140 \pm 82$ & $40 \pm 1.80$ & $23 \pm 1$ & $102,000 \pm 1760$ & 4.6 & $-0.24 \pm 0.05$ \\
\hline$\alpha \mathrm{L} 2100$ & $19 \pm 2$ & $31 \pm 6$ & 1.7 & $93 \pm 4$ & $5180 \pm 167$ & 56 & NA & NA & & $75,600 \pm 1950$ & $920 \pm 40$ & $82 \pm 4.15$ & $25 \pm 1$ & $119,000 \pm 1720$ & 4.8 & $-0.66 \pm 0.06$ \\
\hline$\alpha \mathrm{L} 273 \mathrm{~F}$ & $63 \pm 3$ & $1080 \pm 104$ & 17 & $160 \pm 9$ & $5680 \pm 128$ & 36 & $399 \pm 36$ & $38,300 \pm 2202$ & $0.01 \pm 0.0011$ & $181,400 \pm 1460$ & $739 \pm 23$ & $110 \pm 4.0$ & $22 \pm 1$ & $134,000 \pm 2490$ & 6.1 & $-0.84 \pm 0.05$ \\
\hline$\alpha \mid 274 A$ & $50 \pm 55$ & $331 \pm 400$ & 6.6 & $44 \pm 6$ & $15,800 \pm 1800$ & 359 & NA & NA & & $852 \pm 44$ & $2150 \pm 28$ & $0.40 \pm 0.021$ & $24 \pm 2$ & $124,000 \pm 4520$ & 5.2 & $2.46 \pm 0.06$ \\
\hline$\alpha Y 277 \mathrm{~L}$ & $230 \pm 13$ & $13,300 \pm 450$ & 58 & $440 \pm 740$ & $26,600 \pm 900$ & 60 & NA & NA & NA & $18,100 \pm 330$ & $4800 \pm 56$ & $3.8 \pm 0.12$ & $22 \pm 1$ & $82,000 \pm 2200$ & 3.7 & $1.13 \pm 0.04$ \\
\hline
\end{tabular}

Kinetic parameters and error estimates are derived from global fitting of a kinetic scheme to data obtained over a wide range of ACh concentrations (Materials and Methods). Units are $\mu \mathrm{m}^{-1} \cdot \mathrm{s}^{-1}$ for association rate constants and $\mathrm{s}^{-1}$ for all others. Gating equilibrium constants $(\Theta)$ are ratios of channel opening $(\beta)$ to closing rate $(\alpha)$ constants. NA, Reaction step not detected. Free energy change $\Delta G^{\circ}=-R T \ln (\Theta$ mutant $/ \Theta$ wild type), where $R$ is the gas constant $(1.987$ $\left.\mathrm{cal} /{ }^{\circ} \mathrm{K} / \mathrm{mol}\right)$ and $\mathrm{T}$ is the absolute temperature $\left(295^{\circ} \mathrm{K}\right)$.
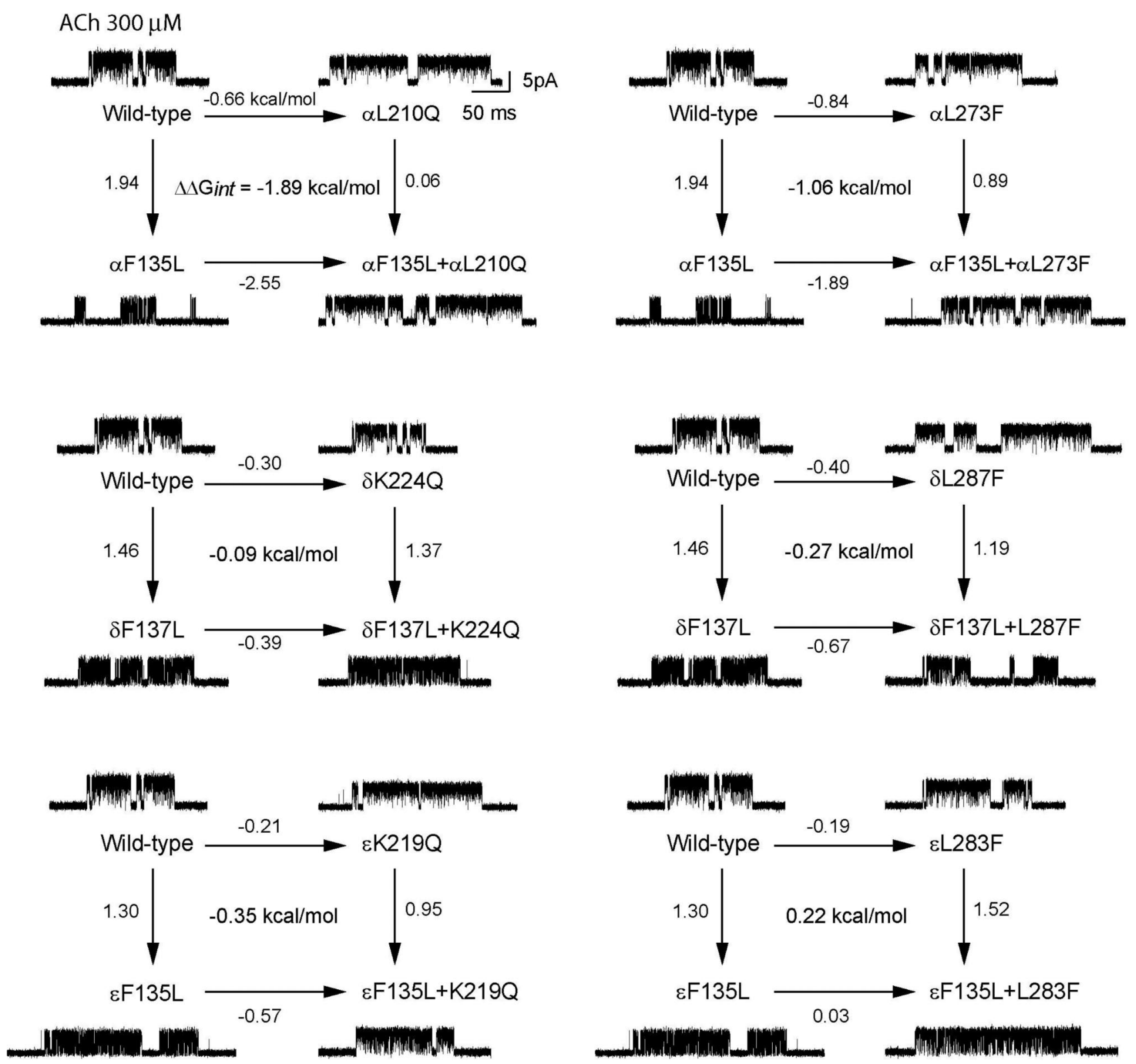

Figure 4. Energetic coupling of $\alpha$ Phe 135 with $\alpha$ Leu 210 and $\alpha$ Leu 273, and coupling among residues at equivalent positions of the $\varepsilon$ - and $\delta$-subunits. In each two-dimensional mutant cycle, the four lines indicate changes in channel gating free energy by the indicated mutations, relative to that for the wild-type AChR; the free energy difference between any pair of parallel lines gives the first-order coupling free energy $\left(\Delta \Delta G_{\text {int }}\right)$ for the residue pair. For each mutant AChR, single-channel currents elicited by $300 \mu \mathrm{m} \mathrm{ACh} \mathrm{are} \mathrm{shown} \mathrm{at} \mathrm{a} \mathrm{bandwidth} \mathrm{of} 10 \mathrm{kHz}$.

channel gating free energy up to $1.5 \mathrm{kcal} / \mathrm{mol}$, but mutations of residues equivalent to $\alpha$ Leu 210 or $\alpha$ Leu 273 alter gating free energy by $0.4 \mathrm{kcal} / \mathrm{mol}$ or less (Table 2). Moreover, the set of two-dimensional mutant cycles reveals negligible first-order cou- pling free energies (Fig. 4, Table 3), indicating residues at equivalent positions of the $\varepsilon$ - and $\delta$-subunits are functionally independent. Mutations of equivalent residues in the $\beta$-subunit have only minor effects on channel gating free energy (Table 2), so mutant 
Table 2. Kinetic analysis of AChRs with mutations in the $\boldsymbol{\beta}-, \boldsymbol{\delta}$-, and $\boldsymbol{\epsilon}$-subunits

\begin{tabular}{|c|c|c|c|c|c|c|c|c|c|c|c|c|c|c|c|c|}
\hline$\overline{A C h R}$ & $k_{+1}$ & $k_{-1}$ & $K_{1}(\mu \mathrm{m})$ & $k_{+2}$ & $k_{-2}$ & $K_{2}(\mu \mathrm{m})$ & $\beta_{1}$ & $\alpha_{1}$ & $\Theta_{1}$ & $\beta_{2}$ & $\alpha_{2}$ & $\Theta_{2}$ & $k_{+\mathrm{b}}$ & $k_{-b}$ & $K_{B}(\mathrm{~mm})$ & $\Delta G^{\circ}(\mathrm{kcal} / \mathrm{mol})$ \\
\hline ild type & $271 \pm 16$ & $7190 \pm 545$ & 26 & $192 \pm 6$ & $19,300 \pm 309$ & 101 & $67 \pm 8$ & 160 & 0.03 & $43,700=$ & $1650 \pm 32$ & $26.5 \pm 0.79$ & $26 \pm 1$ & $113,000 \pm 1690$ & 4.3 & - \\
\hline \multicolumn{17}{|l|}{ Mutant } \\
\hline$\beta F 135 \mathrm{~L}$ & $437 \pm 51$ & $6570 \pm 849$ & 15 & $201 \pm 6.6$ & $21,600 \pm 424$ & 107 & NA & NA & & $53,000 \pm 1380$ & $2640 \pm 65$ & $20 \pm 0.72$ & $19 \pm 1$ & $94,700 \pm 2040$ & 5.0 & $0.16 \pm 0.047$ \\
\hline$\beta F 137 \mathrm{~L}$ & $296 \pm 28$ & $7230 \pm 823$ & 24 & $186 \pm 8$ & $23,100 \pm 481$ & 124 & $148 \pm 20$ & $2180 \pm 186$ & $0.068 \pm 0.011$ & $37,000 \pm 963$ & $1230 \pm 25$ & $30 \pm 0.99$ & $21 \pm 1$ & $105,000 \pm 1640$ & 5.0 & $-0.07 \pm 0.045$ \\
\hline$\beta K 2210$ & $269 \pm 42$ & $3320 \pm 586$ & 12 & $135 \pm 4$ & $21,800 \pm 536$ & 161 & $45 \pm 11$ & $2160 \pm 201$ & $0.021 \pm 0.0055$ & $41,800 \pm 963$ & $1420 \pm 30$ & $29 \pm 0.91$ & $18 \pm 1$ & $112,000 \pm 1820$ & 6.2 & $-0.06 \pm 0.043$ \\
\hline$\beta 1284 \mathrm{~F}$ & $237 \pm 23$ & $5400 \pm 579$ & 20 & $165 \pm 6$ & $22,200 \pm 512$ & 134 & $150 \pm 19$ & $3070 \pm 208$ & $0.049 \pm 0.0070$ & $30,200 \pm 648$ & $2480 \pm 39$ & $12 \pm 0.32$ & $21 \pm 1$ & $102,000 \pm 2010$ & 4.9 & $0.46 \pm 0.040$ \\
\hline$\delta \mathrm{F} 137 \mathrm{~L}$ & $416 \pm 156$ & $10,400 \pm 4020$ & 25 & $243 \pm 17$ & $23,500 \pm 1230$ & 97 & NA & NA & & $11,600 \pm 216$ & $5260 \pm 56$ & $2.2 \pm 0.047$ & $19 \pm 1$ & $90,700 \pm 2610$ & 4.8 & $1.46 \pm 0.037$ \\
\hline$\delta \mathrm{F} 139 \mathrm{~L}$ & $334 \pm 48$ & $4440 \pm 738$ & 13 & $132 \pm 4.6$ & $25,200 \pm 614$ & 191 & $49 \pm 13$ & $2970 \pm 239$ & $0.016 \pm 0.0044$ & $31,000 \pm 849$ & $2890 \pm 55$ & $11 \pm 0.37$ & $18 \pm 1$ & $104,000 \pm 2520$ & 5.8 & $0.53 \pm 0.045$ \\
\hline$\delta K 2240$ & $222 \pm 16$ & $2220 \pm 241$ & 10 & $172 \pm 6.2$ & $11,400 \pm 220$ & 66 & NA & NA & NA & $67,000 \pm 1500$ & $1500 \pm 43$ & $44.5 \pm 1.56$ & $20 \pm 1$ & $115,000 \pm 2390$ & 5.8 & $-0.31 \pm 0.046$ \\
\hline$\delta \mathrm{L} 287 \mathrm{~F}$ & $110 \pm 13$ & $1300 \pm 190$ & 12 & $111 \pm 5.5$ & $20,500 \pm 490$ & 185 & NA & NA & NA & $43,900 \pm 1400$ & $870 \pm 24$ & $50.4 \pm 2.52$ & $18 \pm 1$ & $115,000 \pm 2400$ & 6.4 & $-0.38 \pm 0.056$ \\
\hline$\epsilon \mathrm{F} 135 \mathrm{~L}$ & $420 \pm 140$ & $7200 \pm 2500$ & 17 & $186 \pm 9.3$ & $22,200 \pm 800$ & 119 & NA & NA & NA & $12,500 \pm 210$ & $4300 \pm 40$ & $2.9 \pm 0.060$ & $17 \pm 1$ & $100,000 \pm 2600$ & 5.9 & $1.30 \pm 0.036$ \\
\hline$\epsilon \mathrm{F} 137 \mathrm{~L}$ & $331 \pm 33$ & $5840 \pm 708$ & 18 & $155 \pm 5.4$ & $19,200 \pm 398$ & 124 & $101 \pm 14$ & $2121 \pm 158$ & $0.048 \pm 0.0076$ & $33,400 \pm 771$ & $1650 \pm 29$ & $20 \pm 0.58$ & $22 \pm 1$ & $109,000 \pm 2090$ & 5.0 & $0.16 \pm 0.042$ \\
\hline$\epsilon K 2190$ & $140 \pm 8.8$ & $1200 \pm 110$ & 9 & $170 \pm 5.1$ & $10,700 \pm 180$ & 63 & NA & NA & NA & $59,000 \pm 1010$ & $1550 \pm 33$ & $38 \pm 1.02$ & $21 \pm 1$ & $114,000 \pm 2000$ & 5.4 & $-0.21 \pm 0.040$ \\
\hline$\epsilon \mathrm{L} 283 \mathrm{~F}$ & $181 \pm 15$ & $878 \pm 93$ & 4.9 & $122 \pm 2.8$ & $16,000 \pm 239$ & 131 & NA & NA & & $53,600 \pm 1080$ & $1470 \pm 30$ & $36 \pm 1.03$ & $19 \pm 1$ & $108,000 \pm 2060$ & 5.7 & $-0.19 \pm 0.042$ \\
\hline
\end{tabular}

Table 3. Interresidue energetic coupling determined by mutant cycle analysis

\begin{tabular}{|c|c|c|c|c|c|}
\hline Receptor & $\beta\left(s^{-1}\right)$ & $\alpha\left(s^{-1}\right)$ & $\theta(\beta / \alpha)$ & $\Delta \Delta G_{\text {int }}(\mathrm{kcal} / \mathrm{mol})$ & $\Delta \Delta \Delta G_{\text {int }}(\mathrm{kcal} / \mathrm{mol})$ \\
\hline$\alpha \mathrm{F} 135 \mathrm{~L}-\mathrm{L} 2100$ & $62,000 \pm 2890$ & $835 \pm 52$ & $74 \pm 5.76$ & $-1.89 \pm 0.09$ & \\
\hline$\alpha \mathrm{F} 135 \mathrm{~L}-\mathrm{L} 273 \mathrm{~F}$ & $16,700 \pm 534$ & $687 \pm 15$ & $24 \pm 0.93$ & $-1.06 \pm 0.06$ & \\
\hline$\alpha \mathrm{F} 135 \mathrm{~L}-\mathrm{F} 137 \mathrm{~L}$ & $30,100 \pm 647$ & $3150 \pm 47$ & $9.6 \pm 0.25$ & $-1.11 \pm 0.06$ & \\
\hline$\alpha \mathrm{F} 137 \mathrm{~L}-\mathrm{L} 2100$ & $48,400 \pm 942$ & $473 \pm 10$ & $102 \pm 2.93$ & $0.11 \pm 0.08$ & \\
\hline$\alpha \mathrm{L} 210 \mathrm{Q}-\mathrm{L} 273 \mathrm{~F}$ & $78,900 \pm 2100$ & $510 \pm 25$ & $155 \pm 8.65$ & $0.47 \pm 0.09$ & \\
\hline$\alpha \mathrm{F} 135 \mathrm{~L}-\mathrm{Y} 277 \mathrm{~L}$ & $1870 \pm 25$ & $22,000 \pm 470$ & $0.085 \pm 0.0011$ & $0.29 \pm 0.05$ & \\
\hline$\alpha \mathrm{L} 210 \mathrm{Q}-\mathrm{Y} 277 \mathrm{~L}$ & $83,300 \pm 1720$ & $1550 \pm 48$ & $54 \pm 2.29$ & $-0.91 \pm 0.08$ & \\
\hline$\alpha \mathrm{F} 137 \mathrm{~L}-\mathrm{Y} 277 \mathrm{~L}$ & $56,600 \pm 1510$ & $5410 \pm 150$ & $10.4 \pm 0.40$ & $-0.35 \pm 0.07$ & \\
\hline$\alpha \mathrm{F} 135 \mathrm{~L}-\mathrm{I274A}$ & $74 \pm 1.6$ & $6090 \pm 127$ & $0.012 \pm 0.0004$ & $0.10 \pm 0.07$ & \\
\hline$\alpha \mathrm{L} 273 \mathrm{~F}-\mathrm{I} 274 \mathrm{~A}$ & $604 \pm 34$ & $381 \pm 7$ & $1.59 \pm 0.094$ & $0.02 \pm 0.09$ & \\
\hline$\alpha \mathrm{V} 132 \mathrm{~A}-1274 \mathrm{~A}$ & $423 \pm 29$ & $5690 \pm 215$ & $0.074 \pm 0.01$ & $-0.01 \pm 0.10$ & \\
\hline$\alpha \mathrm{V} 132 \mathrm{~L}-\mathrm{I274A}$ & $63 \pm 1.9$ & $4870 \pm 150$ & $0.013 \pm 0.0006$ & $0.063 \pm 0.084$ & \\
\hline$\alpha \mathrm{P} 272 \mathrm{~A}-1274 \mathrm{~A}$ & $25,400 \pm 1040$ & $857 \pm 21$ & $29.6 \pm 1.41$ & $-1.83 \pm 0.09$ & \\
\hline$\delta$ F137L-K224Q & $11,700 \pm 143$ & $2720 \pm 21$ & $4.30 \pm 0.54$ & $-0.09 \pm 0.05$ & \\
\hline$\delta \mathrm{F} 137 \mathrm{~L}-\mathrm{L} 287 \mathrm{~F}$ & $23,500 \pm 415$ & $3400 \pm 35$ & $6.91 \pm 0.14$ & $-0.27 \pm 0.06$ & \\
\hline$\delta K 2240-\mathrm{L} 287 \mathrm{~F}$ & $39,600 \pm 1443$ & $583 \pm 20$ & $67.9 \pm 3.40$ & $0.16 \pm 0.08$ & \\
\hline$\epsilon \mathrm{F} 135 \mathrm{~L}-\mathrm{K} 2190$ & $35,300 \pm 440$ & $4700 \pm 54$ & $7.5 \pm 0.13$ & $-0.35 \pm 0.05$ & \\
\hline$\epsilon \mathrm{F} 135 \mathrm{~L}-\mathrm{L} 283 \mathrm{~F}$ & $16,700 \pm 271$ & $6130 \pm 56$ & $2.72 \pm 0.051$ & $0.22 \pm 0.05$ & \\
\hline$\epsilon \mathrm{K} 2190-\mathrm{L} 283 \mathrm{~F}$ & $64,400 \pm 998$ & $1330 \pm 30$ & $48.4 \pm 1.32$ & $0.05 \pm 0.06$ & \\
\hline$\alpha \mathrm{F} 135 \mathrm{~L}-\mathrm{L} 210 \mathrm{Q}-\mathrm{L} 273 \mathrm{~F}$ & $76,000 \pm 2600$ & $713 \pm 36$ & $107 \pm 6.5$ & & $1.22 \pm 0.09$ \\
\hline$\alpha \mathrm{F} 135 \mathrm{~L}-\mathrm{F} 137 \mathrm{~L}-\mathrm{L} 210 \mathrm{Q}$ & $79,300 \pm 1340$ & $868 \pm 27$ & $91 \pm 3.2$ & & $1.12 \pm 0.07$ \\
\hline$\alpha \mathrm{F} 135 \mathrm{~L}-\mathrm{L} 210 \mathrm{Q}-\mathrm{Y} 277 \mathrm{~L}$ & $12,400 \pm 379$ & $740 \pm 10$ & $17 \pm 0.57$ & & $0.14 \pm 0.07$ \\
\hline$\alpha \mathrm{F} 135 \mathrm{~L}-\mathrm{F} 137 \mathrm{~L}-\mathrm{Y} 277 \mathrm{~L}$ & $7990 \pm 124$ & $12,300 \pm 95$ & $0.65 \pm 0.011$ & & $0.29 \pm 0.06$ \\
\hline$\alpha \mathrm{F} 135 \mathrm{~L}-\mathrm{L} 273 \mathrm{~F}-\mathrm{I} 274 \mathrm{~A}$ & $253 \pm 32$ & $801 \pm 22$ & $0.32 \pm 0.041$ & & $-0.03 \pm 0.14$ \\
\hline$\alpha \mathrm{V} 132 \mathrm{~A}-\mathrm{P} 272 \mathrm{~A}-\mathrm{I} 274 \mathrm{~A}$ & $5610 \pm 62$ & $2360 \pm 15$ & $2.38 \pm 0.03$ & & $1.16 \pm 0.05$ \\
\hline$\delta$ F137L-K224Q-L287F & $23,800 \pm 741$ & $1820 \pm 104$ & $13.1 \pm 0.85$ & & $-0.13 \pm 0.08$ \\
\hline$\epsilon \mathrm{F} 135 \mathrm{~L}-\mathrm{K} 2190-\mathrm{L} 283 \mathrm{~F}$ & $34,700 \pm 360$ & $3250 \pm 35$ & $10.7 \pm 0.20$ & & $-0.28 \pm 0.05$ \\
\hline
\end{tabular}

Rate constants and error estimates are derived from global fitting of a kinetic scheme to data obtained over a wide range of ACh concentrations (Materials and Methods). Gating equilibrium constants ( $\Theta$ ) are ratios of channel opening $(\beta)$ to closing $(\alpha)$ rate constants. For 2-D mutant cycles, first-order coupling free energies are symbolized $\Delta \Delta G_{\text {int }}$. For 3-D mutant cycles, second-order coupling free energies are symbolized $\Delta \Delta \Delta G_{\text {int }}$.

cycle analyses were not performed for these residues. Thus, energetic coupling among $\alpha$ Phe 135, $\alpha$ Leu 210, and $\alpha$ Leu 273 is unique to the $\alpha$-subunit.

\section{Context dependence of pairwise interresidue coupling}

Interresidue coupling has been widely observed to be context dependent (Zhang et al., 1996; Albeck et al., 2000), particularly for residues within $7 \AA$ of each other (Schreiber and Fersht, 1995). Thus, to determine whether energetic coupling between any two residues of the triad $\alpha$ Phe 135, $\alpha$ Leu 210, and $\alpha$ Leu 273 depends on the third residue, we generated a cubic mutant cycle (Fig. $5 A$ ). The left vertical plane, $\alpha \mathrm{F} 135 \mathrm{~L} / \alpha \mathrm{L} 210 \mathrm{Q}$, exhibits a first-order coupling free energy of $-1.9 \mathrm{kcal} / \mathrm{mol}$, but the opposing plane, in which the mutation $\alpha \mathrm{L} 273 \mathrm{~F}$ is present in all four mutant AChRs, exhibits a decreased coupling free energy of $-0.67 \mathrm{kcal} / \mathrm{mol}$. Analogously, the top plane, $\alpha \mathrm{F} 135 \mathrm{~L} / \alpha \mathrm{L} 273 \mathrm{~F}$, exhibits a coupling free energy of $1.1 \mathrm{kcal} / \mathrm{mol}$, but the opposing plane, in which the mutation $\alpha \mathrm{L} 210 \mathrm{Q}$ is present, exhibits a decreased coupling free energy of $0.16 \mathrm{kcal} / \mathrm{mol}$. Finally, the front plane, $\alpha \mathrm{L} 210 \mathrm{Q} /$ $\alpha \mathrm{L} 273 \mathrm{~F}$, exhibits a coupling free energy of $0.47 \mathrm{kcal} / \mathrm{mol}$, but the opposing plane, in which the mutation $\alpha \mathrm{F} 135 \mathrm{~L}$ is present, exhibits an increased coupling energy of $1.7 \mathrm{kcal} / \mathrm{mol}$. For the overall cubic cycle, the second-order coupling free energy, given by the difference in first-order coupling free energies between any pair of parallel planes, is $1.2 \mathrm{kcal} / \mathrm{mol}$. Thus, $\alpha$ Phe 135, $\alpha$ Leu 210 , and $\alpha$ Leu 273 contribute to channel gating as an interdependent triad.

\section{$\alpha$ Phe 137 is the fourth member of a coupled tetrad}

To determine whether $\alpha$ Phe 137 is energetically coupled to residues of the triad just identified, we generated a cubic mutant cycle composed of mutations of $\alpha$ Phe 137, $\alpha$ Phe 135, and $\alpha$ Leu 210 (Fig. $5 B$ ). The front plane, $\alpha \mathrm{F} 137 \mathrm{~L} / \alpha \mathrm{L} 210 \mathrm{Q}$, exhibits a first-order coupling free energy of $0.11 \mathrm{kcal} / \mathrm{mol}$, but the opposing plane in 


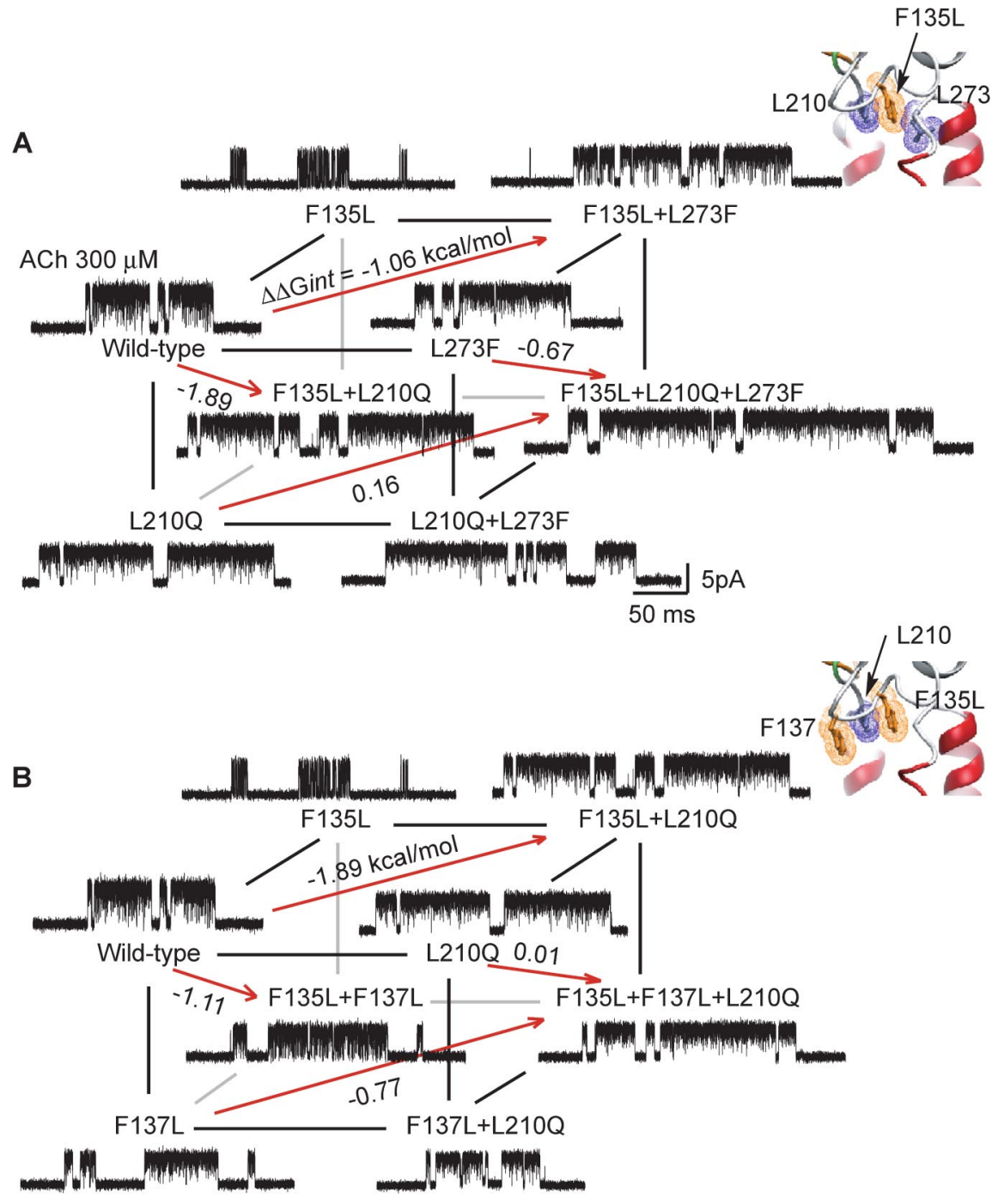

Figure 5. Energetic coupling between $\alpha$ Phe 135, $\alpha$ Phe 137, $\alpha$ Leu 210, and $\alpha$ Leu 273. For a cubic mutant cycle, each plane depicts the first-order coupling free energy $\left(\Delta \Delta G_{\text {int }}\right)$ for the indicated residue pair, as in Figure 4 . The free energy difference between any pair of parallel planes gives the second-order coupling free energy $\left(\Delta \Delta \Delta G_{\text {int }}\right)$ for the residue triad. For each mutant AChR, single-channel currents elicited by $300 \mu \mathrm{m}$ ACh are shown at a bandwidth of $10 \mathrm{kHz}$. $\boldsymbol{A}$, Energetic coupling of $\alpha$ Phe 135, $\alpha$ Leu 210, and $\alpha$ Leu 273. For the front plane, $\Delta \Delta G_{\text {int }}=0.47 \mathrm{kcal} / \mathrm{mol}$, and for the back plane, $\Delta \Delta G_{\text {int }}=1.7 \mathrm{kcal} / \mathrm{mol}$. For this cubic cycle, $\Delta \Delta \Delta G_{\text {int }}=1.2 \mathrm{kcal} / \mathrm{mol}$. $B$, Energetic coupling of $\alpha$ Phe 135, $\alpha$ Phe 137, and $\alpha$ Leu 210. For the front plane, $\Delta \Delta G_{\text {int }}$ $=0.11 \mathrm{kcal} / \mathrm{mol}$, and for the back plane, $\Delta \Delta G_{\text {int }}=1.2 \mathrm{kcal} / \mathrm{mol}$. For this cubic cycle, $\Delta \Delta \Delta G_{\text {int }}=1.1 \mathrm{kcal} / \mathrm{mol}$. Insets show residues examined in each cubic cycle.

which the mutation $\alpha \mathrm{F} 135 \mathrm{~L}$ is present in all four mutant AChRs, exhibits an increased coupling free energy of $1.2 \mathrm{kcal} / \mathrm{mol}$. A possible structural interpretation is that coupling between $\alpha \mathrm{F} 135$ and $\alpha \mathrm{L} 210$ is so strong that mutation of $\alpha$ Phe 137 does not affect the contribution of $\alpha$ Leu 210 to channel gating. However if Leu is substituted for $\alpha$ Phe 135, $\alpha$ Phe 137 remains the nearest aromatic neighbor for $\alpha$ Leu 210, and coupling shifts to this residue pair. The left vertical plane, $\alpha \mathrm{F} 135 \mathrm{~L} / \alpha \mathrm{F} 137 \mathrm{~L}$, exhibits a first-order coupling free energy of $-1.1 \mathrm{kcal} / \mathrm{mol}$, but the opposing plane in which the mutation $\alpha \mathrm{L} 210 \mathrm{Q}$ is present, exhibits a negligible coupling energy of $0.01 \mathrm{kcal} / \mathrm{mol}$. Finally, the top plane, $\alpha \mathrm{F} 135 \mathrm{~L} /$ $\alpha \mathrm{L} 210 \mathrm{Q}$, exhibits a coupling energy of $-1.9 \mathrm{kcal} / \mathrm{mol}$, but the opposing plane, in which the mutation $\alpha \mathrm{F} 137 \mathrm{~L}$ is present, exhibits a decreased coupling energy of $-0.77 \mathrm{kcal} / \mathrm{mol}$. For the overall cubic cycle, the second-order coupling free energy of $1.1 \mathrm{kcal} / \mathrm{mol}$ indicates that $\alpha$ Phe 137, $\alpha$ Leu 210, $\alpha$ Phe 135 contribute to channel gating as a coupled triad. Because both $\alpha$ Leu 210 and $\alpha$ Phe
135 couple strongly to $\alpha$ Leu 273, we infer that $\alpha$ Phe 137 constitutes the fourth member of a coupled tetrad.

\section{Context dependence of residues in the} $\varepsilon$-and $\delta$-subunits

Although only weak energetic coupling is observed among pairs of residues in the $\varepsilon$ and $\delta$-subunits equivalent to $\alpha$ Phe 135 , $\alpha$ Leu 210, and $\alpha$ Leu 273, our analyses of cubic mutant cycles raise the possibility that a neighboring residue may mask interresidue coupling. We therefore generated cubic mutant cycles to examine this possibility, focusing on residues in the $\varepsilon$ and $\delta$-subunits at positions equivalent to $\alpha$ Phe 135, $\alpha$ Leu 210, and $\alpha$ Leu 273. For the cubic mutant cycles generated from the equivalent residue triads, secondorder coupling free energies are low, -0.28 for the triad in the $\varepsilon$-subunit and $-0.13 \mathrm{kcal} / \mathrm{mol}$ for the triad in the $\delta$-subunit (supplemental Fig. S2, available at www.jneurosci.org as supplemental material). Thus, energetic coupling between residues in the Cys-loop, pre-M1 domain, and M2-M3 linker is specific to the $\alpha$-subunit.

\section{$\alpha$ Tyr 277 does not couple to residues in} the tetrad

$\alpha$ Tyr 277 is predicted to project from the distal end of the M2-M3 linker toward the coupled tetrad (Fig. $1 B$ ), and is conserved as an aromatic residue at equivalent positions in all subunits of the Cys-loop receptor superfamily (Fig. 2). Furthermore, mutation of $\alpha$ Tyr 277 to Leu decreases free energy of channel gating by $1.1 \mathrm{kcal} / \mathrm{mol}$ (Table 1). Therefore, to examine energetic coupling among $\alpha$ Tyr 277, $\alpha$ Phe 135, $\alpha$ Phe 137, and $\alpha$ Leu 210, we generated two cubic mutant cycles. In the first cubic cycle (Fig. 6A), the front plane, $\alpha \mathrm{Y} 277 \mathrm{~L} /$ $\alpha \mathrm{L} 210 \mathrm{Q}$, exhibits a first-order coupling free energy of $-0.9 \mathrm{kcal} / \mathrm{mol}$, while the opposing plane, containing the mutation $\alpha \mathrm{F} 135 \mathrm{~L}$, exhibits a coupling energy of $-0.6 \mathrm{kcal} / \mathrm{mol}$. In the second cubic cycle (Fig. $6 B$ ), the front plane, $\alpha \mathrm{Y} 277 \mathrm{~L} / \alpha \mathrm{F} 137 \mathrm{~L}$, exhibits a coupling free energy of $-0.35 \mathrm{kcal} / \mathrm{mol}$, while the opposing plane, containing the mutation $\alpha \mathrm{F} 135 \mathrm{~L}$, maintains a low coupling energy of 0.16 $\mathrm{kcal} / \mathrm{mol}$. For the overall cubic cycles in Figure 6, $A$ and $B$, the second-order coupling free energies are low, 0.33 and $0.51 \mathrm{kcal} /$ mol, respectively. Thus, although $\alpha$ Tyr 277 contributes to channel gating, its contribution depends only weakly on $\alpha$ Leu 210, $\alpha$ Phe 135, and $\alpha$ Phe 137 .

\section{Functional separation of Cys-loop and principal coupling pathways}

The preceding findings show that the Cys-loop is analogous to the $\beta 1-\beta 2$ loop in functionally linking the pre-M1 domain to the M2-M3 linker. To determine whether the Cys-loop and principal coupling pathways overlap functionally, we asked whether $\alpha$ Ile 
274, which is predicted to contact residues from both pathways, couples functionally to residues within either pathway. In particular, $\alpha$ Ile 274 is one of four apparently interlocked aliphatic residues that physically join the Cys-loop to the M2-M3 linker (Fig. 1C), and among Cys-loop receptors, is conserved as Ile or Met (Fig. 2). Furthermore, the mutation $\alpha \mathrm{I} 274 \mathrm{~A}$ decreases free energy of channel gating by 2.5 $\mathrm{kcal} / \mathrm{mol}$, primarily by decreasing the rate constant for channel opening (Table 1); of the mutations examined in this study, $\alpha \mathrm{I} 274 \mathrm{~A}$ affects channel gating to the greatest degree, in broad agreement with previous studies (Jha et al., 2007).

To determine whether the functional contribution of $\alpha$ Ile 274 depends on residues within the Cys-loop coupling pathway, we generated a cubic mutant cycle comprising mutations of $\alpha$ Ile 274 and the two residues in the coupled tetrad predicted to be most proximal, $\alpha$ Phe 135 and $\alpha$ Leu 273 (Fig. 7A). The top and left planes, $\alpha \mathrm{I} 274 \mathrm{~A} / \alpha \mathrm{F} 135 \mathrm{~L}$ and $\alpha \mathrm{I} 274 \mathrm{~A} /$ $\alpha \mathrm{L} 273 \mathrm{~F}$, exhibit first-order coupling free energies of 0.1 and $0.02 \mathrm{kcal} / \mathrm{mol}$, respectively, while the opposing planes, containing a mutation of the third residue, maintain low coupling energies of 0.06 and $-0.02 \mathrm{kcal} / \mathrm{mol}$. The front plane, $\alpha \mathrm{F} 135 \mathrm{~L} /$ $\alpha \mathrm{L} 273 \mathrm{~F}$, exhibits a coupling free energy of $-1.06 \mathrm{kcal} / \mathrm{mol}$, while the opposing plane, containing the mutation $\alpha \mathrm{I} 274 \mathrm{~A}$, exhibits a coupling energy of $-1.1 \mathrm{kcal} / \mathrm{mol}$. For the overall cubic cycle, the second-order coupling free energy is $-0.04 \mathrm{kcal} / \mathrm{mol}$, showing that although $\alpha$ Ile 274 contributes strongly to channel gating, its contribution does not depend on $\alpha$ Phe 135 and $\alpha$ Leu 273 within the Cys-loop coupling pathway.

To determine whether the functional contribution of $\alpha$ Ile 274 depends on residues within the principal coupling pathway, we generated a cubic mutant cycle including mutations of $\alpha \mathrm{Val} 132$ and $\alpha$ Pro 272, which contribute to the principal coupling pathway (Lee and Sine, 2005; Lee et al., 2008) (Fig. 7B). The front plane, $\alpha \mathrm{I} 274 \mathrm{~A} /$ $\alpha \mathrm{V} 132 \mathrm{~A}$, exhibits a negligible first-order coupling free energy, but the opposing plane, containing the mutation $\alpha \mathrm{P} 272 \mathrm{~A}$, exhibits a coupling energy of $1.2 \mathrm{kcal} / \mathrm{mol}$. Conversely, the left plane, $\alpha \mathrm{I} 274 \mathrm{~A} / \alpha \mathrm{P} 272 \mathrm{~A}$, exhibits a large first-order coupling energy of $-1.8 \mathrm{kcal} / \mathrm{mol}$, but the opposing plane, containing the mutation $\alpha \mathrm{V} 132 \mathrm{~A}$, exhibits a reduced coupling energy of $-0.67 \mathrm{kcal} / \mathrm{mol}$. For the overall cubic cycle, the second-order coupling free energy of $-1.2 \mathrm{kcal} / \mathrm{mol}$ shows that the strong contribution of $\alpha$ Ile 274 to channel gating depends on $\alpha \mathrm{Val} 132$ and $\alpha$ Pro 272 of the principal coupling pathway.

\section{Discussion}

The present findings reveal pairwise energetic coupling among residues of the Cys-loop and those in the neighboring pre-M1 and $\mathrm{M} 2-\mathrm{M} 3$ regions, and show that these interresidue couplings
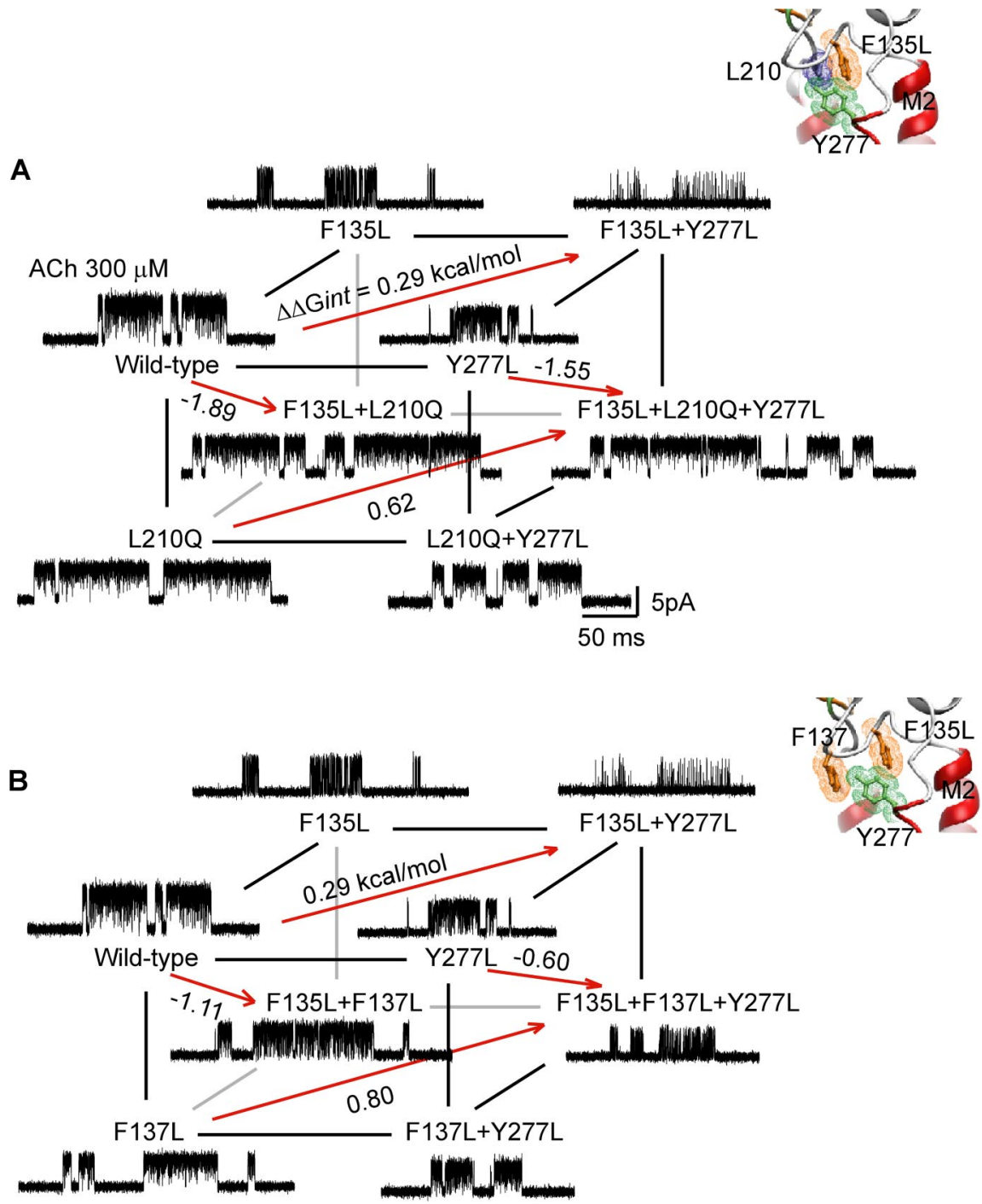

Figure 6. Energetic coupling between $\alpha$ Phe 135, $\alpha$ Phe 137, $\alpha$ Leu 210, and $\alpha$ Tyr 277. A, Energetic coupling of $\alpha$ Phe 135, $\alpha$ Leu 210, and $\alpha \operatorname{Tyr} 277$. For the front plane, $\Delta \Delta G_{\text {int }}=-0.89 \mathrm{kcal} / \mathrm{mol}$, and for the back plane, $\Delta \Delta G_{\text {int }}=-0.56 \mathrm{kcal} / \mathrm{mol}$. For $\Delta \Delta G_{\text {int }}=-0.35 \mathrm{kcal} / \mathrm{mol}$, and for the back plane, $\Delta \Delta G_{\text {int }}=0.16 \mathrm{kcal} / \mathrm{mol}$. For this cubic cycle, $\Delta \Delta \Delta G_{\text {int }}=-0.51 \mathrm{kcal} / \mathrm{mol}$. Insets show residues examined in each cubic cycle.

are essential for rapid and efficient gating of the AChR channel. The emerging network of coupled residues is present in all $\alpha$-subunits that form heteromeric AChRs $\left(\alpha_{1}-\alpha_{6}\right)$, suggesting that it is generally important in transducing agonist binding into channel gating. Energetic coupling is observed only among residues in the $\alpha$-subunits, analogous to interresidue coupling in the previously identified principal coupling pathway (Lee and Sine, 2005). The contribution of the Cys-loop to transduction is analogous to that of the $\beta 1-\beta 2$ loop of the principal coupling pathway in that both loops link the pre-M1 to the M2-M3 region. $\alpha$ Ileu 274 in the M2-M3 linker does not couple energetically to residues in the Cys-loop pathway, but it couples strongly to residues in the principal pathway, suggesting that the two pathways are functionally separate. The strongest interresidue coupling free energies are observed between residues predicted to be nearest neighbors based on the cryo-electron microscopic Torpedo AChR structure, and as widely observed in proteins, the coupling energies are context dependent. Moreover, in light of recent highresolution structures of bacterial Cys-loop receptors in candidate 

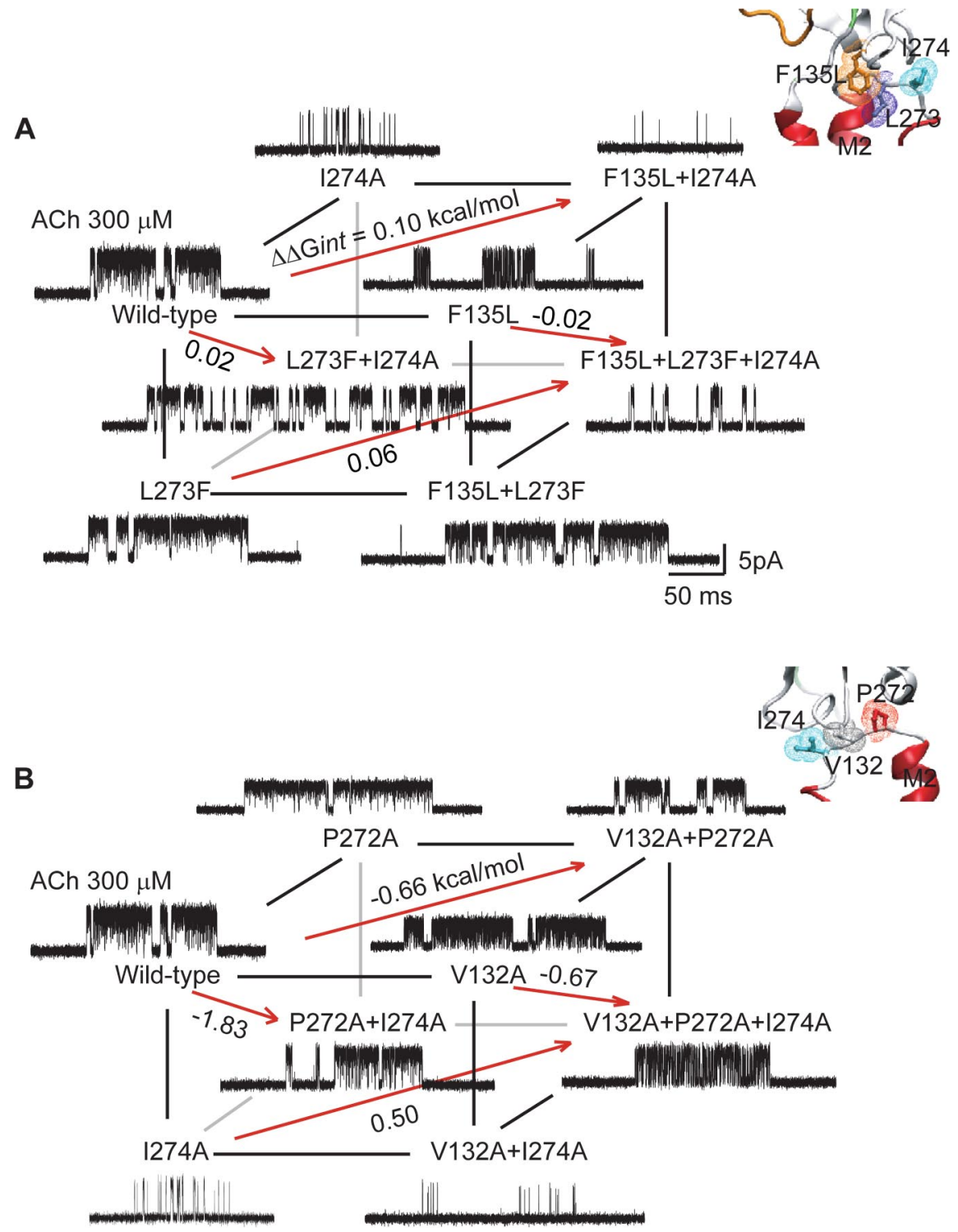

Figure 7. Energetic coupling between $\alpha$ lle 274 and residues in the Cys-loop or principal coupling pathways. $A$, Energetic coupling of $\alpha$ Phe 135, $\alpha$ Leu 210, and $\alpha$ lle 274. For the front plane, $\Delta \Delta G_{\text {int }}=-1.06 \mathrm{kcal} / \mathrm{mol}$, and for the back plane, $\Delta \Delta G_{\text {int }}$ $=-1.1 \mathrm{kcal} / \mathrm{mol}$. For this cubic cycle, $\Delta \Delta \Delta G_{\text {int }}=-0.04 \mathrm{kcal} / \mathrm{mol}$. $B$, Energetic coupling of $\alpha$ Pro 272, $\alpha$ Val 132, and $\alpha$ lle 274 . For the front plane, $\Delta \Delta G_{\text {int }}=-0.01 \mathrm{kcal} / \mathrm{mol}$, and for the back plane, $\Delta \Delta G_{\text {int }}=1.2 \mathrm{kcal} / \mathrm{mol}$. For this cubic cycle, $\Delta \Delta \Delta G_{\text {int }}$ $=-1.2 \mathrm{kcal} / \mathrm{mol}$. Insets show residues examined in each cubic cycle.

closed and open conformations (Bocquet et al., 2009; Hilf and Dutzler, 2009), our findings suggest the principal and Cys-loop pathways contribute jointly in transducing agonist binding to gating of the AChR channel.

Our experimental strategy centers on the use of double mutant cycle analyses to assess interresidue interactions (Horovitz and Fersht, 1990; Horovitz et al., 1990). Mutant cycle analysis is founded on the principle that mutation of a residue causes a free energy change, $\Delta G_{1}$, which depends on other residues within the protein. If mutation of a second residue alters the effect of mutation of the first residue, yielding a different free energy change, $\Delta G_{2}$, the two residues are deemed to interact with a first-order coupling free energy, $\Delta \Delta G=\Delta G_{2}-\Delta G_{1}$. Interresidue coupling free energy is a thermodynamic parameter, and does not disclose whether coupling arises through a direct or a propagated interaction. However, if the two residues are known to make contact, the most likely interpretation is that in the context of the sur- rounding structure, the coupling arises through direct contact. Because resolution of the Torpedo AChR is not sufficient to unequivocally establish direct residue contact, the interresidue coupling free energies could have arisen either through direct contact or through interresidue interactions within an $\sim 7 \AA$ radius. However, it is worth noting that the interresidue couplings observed here support residue placement in the cryo-electron microscopic structure of the Torpedo AChR (Unwin, 2005).

The cryo-electron microscopic structure of the Torpedo AChR nevertheless establishes that the Cys-loop inserts between the pre-M1 domain and the M2-M3 loop. Residues stemming from these structures ( $\alpha$ Leu 210, $\alpha$ Phe 137, $\alpha$ Phe 135, and $\alpha$ Leu 273 ) are predicted to project into the space underneath the Cys-loop and face the pore, forming a row of alternating aliphatic and aromatic side chains approximately parallel to the plane of the membrane. The high-resolution structures of the bacterial homologs ELIC and GLIC confirm the overall placement of the Cysloop in the lower resolution Torpedo AChR structure, but the detailed shape, orientation relative to the membrane, and pairwise residue contacts of the Cys-loop differ between Torpedo AChR and bacterial counterparts. Nevertheless, in both Torpedo and bacterial structures, the C-terminal half of the Cys-loop associates with the pre-M1 domain, the $\mathrm{N}$-terminal half associates with the M2-M3 linker, and the prevalent interresidue contacts are hydrophobic. In both the inactive ELIC and active GLIC structures, the Cys-loop maintains close association with surrounding residues (Bocquet et al., 2009; Hilf and Dutzler, 2009), suggesting that the interresidue couplings detected here originate from interresidue contacts that are maintained between closed and open states, rather than from contacts that form or break upon transition between the two states.

Throughout this work, the kinetics of AChR activation was analyzed using a kinetic model in which two agonists bind sequentially, the channel gates, and ACh blocks the open channel (Materials and Methods). A recent study, however, provided evidence for a transient closed state, called flipped, that followed agonist binding but preceded channel opening (Lape et al., 2008). The flipped state was suggested to be a major determinant of agonist efficacy, forming with much greater efficiency for full agonists compared with partial agonists. It is possible that mutations examined in this study, rather than altering elementary steps underlying agonist binding or channel gating, altered elementary steps underlying flipping. However, introducing a flipped state into the kinetic model increases the number of free parameters and thus substantially increases the difficulty of obtaining well defined rate constants. In recognition of this poten- 
tial limitation, we emphasize that the rate constants underlying agonist binding and channel gating presented here should be considered apparent rate constants.

The chief coupling free energies identified herein correspond to the residue pairs $\alpha$ Phe $135 / \alpha$ Leu 210, $\alpha$ Phe135/ $\alpha$ Leu273, and $\alpha$ Phe135/ $\alpha$ Phe137. The coupling free energies likely arise from optimal tertiary packing of side chains that buries large hydrophobic surfaces. In model peptides that can form $\alpha$-helices, pairs of aromatic or pairs of aromatic and Leu residues stabilize the helix when placed at positions $i$ and $i+4$ of the peptide chain, in contrast to lack of stabilization by pairs of aliphatic residues; the stabilization was suggested to arise from decreased loss of conformational entropy for aromatic-aliphatic compared with aliphatic-aliphatic pairs (Padmanabhan and Baldwin, 1994; Creamer and Rose, 1995). The cubic cycle $\alpha$ F135L/ $\alpha$ L210Q/ $\alpha$ L273F exhibits a second-order coupling free energy of $1.2 \mathrm{kcal} / \mathrm{mol}$ and provides evidence that the interresidue triad is energetically coupled. This coupling energy is about half of that determined for residue triads from the principal coupling pathway, $\alpha \mathrm{V} 46 \mathrm{~A} /$ $\alpha \mathrm{P} 272 \mathrm{G} / \alpha$ S269L $(-2.0 \mathrm{kcal} / \mathrm{mol})$ (Lee and Sine, 2005) and $\alpha \mathrm{V} 132 \mathrm{~A} / \alpha \mathrm{V} 46 \mathrm{~A} / \alpha \mathrm{P} 272 \mathrm{~A}(2.3 \mathrm{kcal} / \mathrm{mol})$ (Lee et al., 2008). Tertiary packing of hydrophobic side chains is likely a major source of interresidue energetic coupling in both the Cys-loop and principal transduction pathways.

Conformational rearrangements underlying transduction of binding to gating have been detected in two distinct regions of the representative Cys-loop receptor: the agonist binding site and the structural transition zone between extracellular and pore domains. The collective evidence suggests a structural mechanism of the transduction process, described as follows.

In the absence of agonist, the peripheral C-loop tilts away from the binding site, maintaining an opened up conformation that allows small molecules to enter the site. Supporting evidence comes from $x$-ray structures of the homologous AChBP (Celie et al., 2004; Hansen et al., 2005), the bacterial channel ELIC (Hilf and Dutzler, 2008), and the cryo-electron microscopic structure of the Torpedo AChR (Unwin, 2005), all in the absence of activators. After the activator binds, the C-loop changes from an uncapped to a capped conformation, restricting exit or entry of small molecules, again as demonstrated by x-ray structures of $\mathrm{AChBP}$ and the bacterial channel GLIC in the presence of activators. Notably, the only comparison of liganded and unliganded structures for the same protein was achieved for AChBP from Aplysia (Hansen et al., 2005). In solution, activator-induced changes of the C-loop have been observed for Lymnaea AChBP through measurements of intrinsic tryptophan fluorescence (Gao et al., 2005), changes in chemical shift by NMR (Gao et al., 2006), and molecular dynamics simulations (Gao et al., 2005; Cheng et al., 2006b). Thus, the accumulated evidence indicates that the initial trigger for channel gating is a capping motion of the C-loop (Mukhtasimova et al., 2005).

Attention has also focused on the junction between the extracellular and pore domains, because this region features an abrupt transition where $\beta$-sheets meet $\alpha$-helices. Within this transition zone of each AChR subunit, five segments from different parts of the linear sequence merge: three loops from the extracellular domain, the covalent link between the extracellular and pore domains, and the linker joining the M2 and M $3 \alpha$-helices. A wealth of structure-function studies show that residues from all five intrazone segments are crucial for coupling agonist binding to channel gating (for review, see Sine and Engel, 2006). In particular, a highly conserved salt bridge within the hydrophobic core of the $\alpha$-subunits joins, both physically and functionally, the
pre-M1 domain to the tip of the $\beta 1-\beta 2$ loop (Lee and Sine, 2005; Unwin, 2005). The $\beta 1-\beta 2$ loop, in turn, forms a hydrophobic pin-in-socket connection to the M2-M3 linker at the top of the pore (Unwin, 2005). This triad of interlinked segments, called the principal coupling pathway, was originally identified in light of the $4 \AA$ resolution cryo-electron microscopic structure of the Torpedo AChR. However the positioning of key elements of the principal pathway, such as the buried salt bridge formed by Arg 209 and Glu 45, have been verified by high-resolution structures of the isolated $\alpha$-subunit extracellular domain (Dellisanti et al., 2007) and the bacterial channel GLIC (Hilf and Dutzler, 2008) and by structure-function studies of the homomeric $\rho_{1}$ GABA receptor (Wang et al., 2007).

Comparison of $\mathrm{x}$-ray structures of ELIC in the inactive state and GLIC in the active state suggest that agonist binding causes translation of the $\beta 1-\beta 2$ loop against the M2-M3 linker, displacing the tops of the M2 and M3 $\alpha$-helices away from an axis through the center of the channel, thus initiating ion conduction (Bocquet et al., 2009; Hilf and Dutzler, 2009). Although the $\beta$-strands stemming from the $\beta 1-\beta 2$ loop do not connect directly to the agonist binding site, interstrand hydrogen bonds hold these strands within the overall $\beta$-barrel structure, which also encompasses elements that form the principal face of the agonist binding site. Thus, when the C-loop caps the entrance to the binding site, a quaternary twist of the overall $\beta$-barrel (Taly et al., 2006; Cheng et al., 2006a) could cause translation of the $\beta 1-\beta 2$ loop against the M2-M3 linker and consequently open the channel.

If the link between the pre-M1, $\beta 1-\beta 2$, and $\mathrm{M} 2-\mathrm{M} 3$ regions is a principal trigger of channel gating, how does the Cys-loop contribute to gating? Structures of the Torpedo AChR and bacterial channels show that the $\beta 1-\beta 2$ loop overlies the M2-M3 linker and is proximal to an axis through the center of the channel, whereas the larger Cys-loop inserts between the M2-M3 linker and the pre-M1 domain, and is farther from the central axis. The four $\beta$-strands that emanate from the $\beta 1-\beta 2$ and Cys-loops are hydrogen bonded within the overall $\beta$-barrel structure, so a quaternary twist of the barrel would likely move both loops in concert. The two loops impinge on opposite sides and at opposite ends of the M2-M3 linker, which extends radially from the central axis. Studies of linear free energy relationships of channel gating reveal similar slopes of the plot of channel opening rate against channel opening equilibrium constant for the $\beta 1-\beta 2$ and Cys-loops (Jha et al., 2007), suggesting the two loops change conformation at the same time. A concerted movement of the two loops would displace the linker away from the central axis, moving the tops of the M2 and M $3 \alpha$-helices in the same direction, dilating the top of the pore (Bocquet et al., 2009; Hilf and Dutzler, 2009). Thus, through specific interresidue couplings, the $\beta 1-\beta 2$ and Cys-loops loops appear to act jointly on M2-M3 linker to open the pore for ion conduction. Upon relaxation of the twisted $\beta$-barrel, return of the $\beta 1-\beta 2$ and Cys-loops to their original positions would constrict the top of the pore, closing the channel.

\section{References}

Albeck S, Unger R, Schreiber G (2000) Evaluation of direct and cooperative contributions towards the strength of buried hydrogen bonds and salt bridges. J Mol Biol 298:503-520.

Armstrong N, Sun Y, Chen GQ, Gouaux E (1998) Structure of a glutamatereceptor ligand-binding core in complex with kainate. Nature 395:913-917.

Bocquet N, Nury H, Baaden M, Le Poupon C, Changeux JP, Delarue M, 
Corringer PJ (2009) X-ray structure of a pentameric ligand-gated ion channel in an apparently open conformation. Nature 457:111-114.

Brejc K, van Dijk WJ, Klaassen RV, Schuurmans M, van Der Oost J, Smit AB, Sixma TK (2001) Crystal structure of an ACh-binding protein reveals the ligand-binding domain of nicotinic receptors. Nature 411:269-276.

Carter PJ, Winter G, Wilkinson AJ, Fersht AR (1984) The use of double mutants to detect structural changes in the active site of the tyrosyl-tRNA synthetase (Bacillus stearothermophilus). Cell 38:835-840.

Celie PH, van Rossum-Fikkert SE, van Dijk WJ, Brejc K, Smit AB, Sixma TK (2004) Nicotine and carbamylcholine binding to nicotinic acetylcholine receptors as studied in AChBP crystal structures. Neuron 41:907-914.

Chakrapani S, Bailey TD, Auerbach A (2004) Gating dynamics of the acetylcholine receptor extracellular domain. J Gen Physiol 123:341-356.

Cheng X, Lu B, Grant B, Law RJ, McCammon JA (2006a) Channel opening motion of alpha7 nicotinic acetylcholine receptor as suggested by normal mode analysis. J Mol Biol 355:310-324.

Cheng X, Wang H, Grant B, Sine SM, McCammon JA (2006b) Targeted molecular dynamics study of C-loop closure and channel gating in nicotinic receptors. PLoS Comput Biol 2:e134.

Colquhoun D, Sigworth F (1983) Fitting and statistical analysis of single channel records. In: Single-channel recording (Sakmann B, Neher E, eds), pp 191-264. New York: Plenum.

Creamer TP, Rose GD (1995) Interactions between hydrophobic side chains within a-helices. Protein Sci 4:1305-1314.

Dellisanti CD, Yao Y, Stroud JC, Wang ZZ, Chen L (2007) Crystal structure of the extracellular domain of nAChR $\alpha 1$ bound to $\alpha$-bungarotoxin at 1.94 Å resolution. Nat Neurosci 10:953-962.

Fu DX, Sine SM (1996) Asymmetric contribution of the conserved disulfide loop to subunit oligomerization and assembly of the nicotinic acetylcholine receptor. J Biol Chem 271:31479-31484.

Gao F, Bren N, Burghardt TP, Hansen S, Henchman RH, Taylor P, McCammon JA, Sine SM (2005) Acetylcholine-mediated conformational changes in acetylcholine-binding protein revealed by simulation and intrinsic tryptophan fluorescence. J Biol Chem 280:8443-8451.

Gao F, Mer G, Tonelli M, Hansen SB, Burghardt TP, Taylor P, Sine SM (2006) Solution NMR of acetylcholine binding protein reveals agonistmediated conformational change of the C-loop. Mol Pharmacol 70:1230-1235.

Green WN, Wanamaker CP (1997) The role of the cystine loop in acetylcholine receptor assembly. J Biol Chem 272:20945-20953.

Hansen SB, Sulzenbacher G, Huxford T, Marchot P, Taylor P, Bourne Y (2005) Structures of Aplysia AChBP complexes with nicotinic agonists and antagonists reveal distinctive binding interfaces and conformations. EMBO J 24:3635-3646.

Hilf RJ, Dutzler R (2008) X-ray structure of a prokaryotic pentameric ligand-gated ion channel. Nature 452:375-379.

Hilf RJ, Dutzler R (2009) Structure of a potentially open state of a protonactivated pentameric ligand-gated ion channel. Nature 457:115-118.

Horovitz A, Fersht AR (1990) Strategy for analysing the co-operativity of intramolecular interactions in peptides and proteins. J Mol Biol 214:613617.

Horovitz A, Serrano L, Avron B, Bycrogt M, Fersht AR (1990) Strength and cooperativity of contributions of surface salt bridges to protein stability. J Mol Biol 216:1031-1044.

Jha A, Cadugan DJ, Purohit P, Auerbach A (2007) Acetylcholine receptor gating at extracellular transmembrane domain interface: the cys-loop and m2-m3 linker. J Gen Physiol 130:547-558.

Lape R, Colquhoun D, Sivilotti LG (2008) On the nature of partial agonism in the nicotinic receptor superfamily. Nature 454:722-727.

Lee BS, Gunn RB, Kopito RR (1991) Functional differences among nonerythroid anion exchangers expressed in a transfected human cell line. J Biol Chem 266:11448-11454.

Lee WY, Sine SM (2004) Invariant aspartic acid in muscle nicotinic receptor contributes selectively to the kinetics of agonist binding. J Gen Physiol 124:555-567.

Lee WY, Sine SM (2005) Principal pathway coupling agonist binding to channel gating in nicotinic receptors. Nature 438:243-247.

Lee WY, Free C, Sine SM (2008) Nicotinic receptor inter-loop proline anchors $\beta 1-\beta 2$ and Cys-loops in coupling agonist binding to channel gating. J Gen Physiol 132:265-278.

Mukhtasimova N, Free C, Sine SM (2005) Initial coupling of binding to gating mediated by conserved residues in muscle nicotinic receptor. J Gen Physiol 126:23-39.

Ohno K, Wang HL, Milone M, Bren N, Brengman JM, Nakano S, Quiram P, Pruitt JN, Sine SM, Engel AG (1996) Congenital myasthenic syndrome caused by decreased agonist binding affinity due to a mutation in the acetylcholine receptor epsilon subunit. Neuron 17:157-170.

Padmanabhan S, Baldwin RL (1994) Tests for helix-stabilizing interactions between various nonpolar side chains in alanine-based peptides. Protein Sci 3:1992-1997.

Purohit P, Auerbach A (2007) Acetylcholine receptor gating at extracellular transmembrane domain interface: the "pre-M1" linker. J Gen Physiol 130:559-568.

Qin F, Auerbach A, Sachs F (1996) Estimating single-channel kinetic parameters from idealized patch-clamp data containing missed events. Biophys J 70:264-280.

Schreiber G, Fersht AR (1995) Energetics of protein-protein interactions: analysis of the barnase-barstar interface by single mutations and double mutant cycles. J Mol Biol 248:478-486.

Sine SM, Engel AG (2006) Recent advances in Cys-loop structure and function. Nature 440:448-455.

Sine SM, Steinbach JH (1987) Activation of acetylcholine receptors on clonal mammalian $\mathrm{BC} 3 \mathrm{H}-1$ cells by high concentrations of agonist. J Physiol 385:325-359.

Taly A, Corringer PJ, Grutter T, Prado de Carvalho L, Karplus M, Changeux JP (2006) Implications of the quaternary twist allosteric model for the physiology and pathology of nicotinic receptors. Proc Natl Acad Sci U S A 103:16965-16970.

Unwin N (2005) Refined structure of the nicotinic acetylcholine receptor at $4 \AA$ resolution. J Mol Biol 346:967-989.

Wang HL, Auerbach A, Bren N, Ohno K, Engel AG, Sine SM (1997) Mutation in the M1 domain of the acetylcholine receptor alpha subunit decreases the rate of agonist dissociation. J Gen Physiol 109:757-766.

Wang J, Lester HA, Dougherty DA (2007) Establishing an ion pair interaction in homomeric rhol gamma-aminobutyric acid type A receptor that contributes to the gating pathway. J Biol Chem 282:26210-26216.

Zhang H, Skinner MM, Sandberg WS, Wang AH, Terwilliger TC (1996) Context dependence of mutational effects in a protein: the crystal structures of the V35I, I47V and V35I/I47V gene V protein core mutants. J Mol Biol 259:148-159. 